\title{
Bayesian Networks for the management of Greenhouse Gas emissions in the British agricultural sector
}

\author{
E. Pérez-Miñana ${ }^{1}$, P. Krause ${ }^{1}$, J. Thornton ${ }^{2}$ \\ ${ }^{1}$ Department of Computing, Faculty of Engineering and Physical Science, University of Surrey, Guildford, Surrey, GU2 7XH, UK \\ ${ }^{2}$ Welsh School of Architecture, Cardiff University, Bute Building, King Edward VII Avenue, Cardiff CF10 3NB, Wales \\ Elena.Perezminana@btinternet.com,p.krause@surrey.ac.uk,ThorntonJM@cardiff.ac.uk
}

\begin{abstract}
Recent years have witnessed a rapid rise in the development of deterministic and nondeterministic models to estimate human impacts on the environment. An important failing of these models is the difficulty that most people have understanding the results generated by them, the implications to their way of life and also that of future generations. Within the field, the measurement of greenhouse gas emissions $(\mathrm{GHG})$ is one such result. The research described in this paper evaluates the potential of Bayesian Network (BN) models for the task of managing GHG emissions in the British agricultural sector. Case study farms typifying the British agricultural sector were inputted into both, the BN model and CALM, a Carbon accounting tool used by the Country Land Business Association (CLA) in the UK for the same purpose. Preliminary results show that the $\mathrm{BN}$ model provides a better understanding of how the tasks carried out on a farm impact the environment through the generation of GHG emissions. This understanding is achieved by translating the emissions information into their cost in monetary terms using the Shadow Price of Carbon (SPC), something that is not possible using the CALM tool. In this manner, the farming sector should be more inclined to deploy measures for reducing its impact. At the same time, the output of the analysis can be used to generate a business plan that will not have a negative effect on a farm's capital income.
\end{abstract}

Keywords: GHG Emissions, Environmental factors, Bayesian Networks. 


\section{Introduction}

It has been estimated that agriculture could be contributing somewhere in the range of 10-30\% of Greenhouse Gas emissions (GHGe) (Bellarby et al., 2008) (Neftel et al., 2006). Hence, it is critically important that we develop comprehensive tools to assess and manage GHGe from the agricultural sector that can incorporate both activities, i.e. those providing the means to sequester GHGe such as soil management practices, and those that release GHGe, such as livestock farming. However, calculating the impact of these activities is a difficult problem. Many variables are involved, often with high levels of uncertainty associated with both their measurement and their mechanism of influence on the state of the biosphere. It is usually unfeasible to monitor them all, difficult to set the boundaries of what needs to be measured, or determine to what extent it is affected by elements that are external to the activity of interest (Clark 2005; Smith 2007). The second difficulty is that of explaining these effects to the individuals involved in the respective activities, in a way that will induce behavioural changes (Cain et al., 2003).

We have developed a probabilistic model for farm-scale assessment of Greenhouse Gas emissions (GHGe). The relative merits of probabilistic and deterministic modelling approaches have been discussed extensively in the literature, e.g. Aalders (2008), Clark (2005), Voorspools (2005), Wiggering et al. (2006). The inherent uncertainties associated with GHG estimation suggest a probabilistic modelling approach is appropriate. The variety in the type and number of factors that must be taken into consideration is high; there is considerable uncertainty surrounding the impacts of these factors; and significant complexities exist in terms of the inter-dependencies. Effects on a farm s financial performance are also difficult to quantify.

Our choice of technology, Bayesian Networks (BNs), has been motivated by the need to: (a) explicitly handle the uncertainties involved; and, (b) provide a graphical representation of the causal influences in order to explain simply the relevance of any proposed intervention. An important feature of our model is that a farm's environmental impact is integrated into its economic profile, in order to monetise the impacts of the GHG emitted. The situating of our modelling work within the context of classical decision theory thus provides a tight coupling between environmental and economic factors (Pérez-Miñana 2009). Users of the tool are able to hypothesise different production scenarios, and then use the model to predict the environmental and economic impact each one has. We can thus use the model to identify preemptive actions that have a minimal (or even a positive) impact on the economic viability of a farm. 
If we can demonstrate that the implementation of net-GHG negative processes such as carbon sequestration via land management practices (Hutchinson et al., 2007; McCarl et al., 2007; Zero Carbon Britain, 2010) can be economically viable, then we can realise the potential of the agriculture sector to help mitigate the risks of global warming. Given that the agricultural sector is particularly reliant on natural capital for its economic gains (Ekins, 2003), and in many countries is also supported by government subsidy, we believe that it is vitally important that tools such as the one we propose be used to aid both management choices at the level of the farm, and choices by policy makers, such as levels of subsidy or grant aid. This dual purpose of the tool is an important benefit of its design.

The need to formalise the inter-dependencies between financial and environmental profiles is also suggested in the approach proposed in (Wiggering et al., 2006). Further evidence is shown in the reform to the Common Agricultural Policy (CAP) supported by the Organization for Economic Co-operation and Development (OECD), and the European Union (EU). The CAP reflects a need for managing land use by merging both the economic and ecological aspects of the agricultural sector.

As DEFRA's preferred indicator for the relationship between economics and the environment is the SPC (DEFRAEconomics Group, 2007), and this department is the main governmental body responsible for deciding and deploying environmental policies in all sectors in the UK, it is appropriate to consider the same economic tool for costing the effects of the GHG emitted on a particular farm.

We describe the method we followed to construct our model in the next section. We constructed our model with detailed reference to the IPCC guidelines for GHG estimation (IPCC, 2006). The IPCC guidelines were also a primary source of reference for the CALM calculator, a Carbon accounting tool that has been developed by the Country Landowners Association (CLA) and Savills for the agricultural sector (CLA, 2010). We will explain how we compared our tool against the CALM tool. In section 3, we present the results obtained through using our model in some exemplar scenarios and comparisons with CALM. Our findings are discussed in section 4, with a specific focus on the capabilities of our specific choice of modelling technique. Finally, we conclude the paper with a summary of some of the research challenges that still remain in the modelling of greenhouse gas emission in the agricultural sector. 


\section{Material and Methods}

This section describes the process followed to develop the model's architecture, and the underlying probabilistic model.

\subsection{Modelling Process}

The tools available to build BN models (such as: HUGIN EXPERT, 2010; AgenaRisk, 2010; Norsys, 2010) include features for editing, compiling and executing them. Nevertheless methods and tools supporting the BN development process are not widely available (Gras \& McGaw, 2004). Consequently, BN users need to develop their own approach which broadly comprises the following steps:

- Identification of all the variables relevant to the application domain, their data type and scale;

- Elicitation and quantification of the inter-dependencies that exist between these variables.

It is usually fairly straightforward to analyse a specific problem domain to identify the relevant variables, and the qualitative influences or cause-effect relationships between them. However, defining node scales and determining the conditional probability tables (CPTs) that quantify the inter-dependencies between the variables is a much harder problem, given that the number of parameters grows exponentially with the number of parent-nodes involved in the interdependencies (Das 1999). This becomes computationally intractable when the application domain requires a nonstandard high dimensional statistical model with inter-mixed continuous and discrete variables, which is fairly common in most practical applications (Fenton et al., 1999).

The knowledge elicitation problem has been tackled in different ways by different researchers, e.g. (Ma et al., 2007; Dlamani, 2010; Newton, 2010), but they all comprise one or more of the following activities:

1. Discretisation of the domain factors, a necessary step to be able to use the network development environment, e.g. Netica (Norsys, 2010), (Dlamani, 2010; Newton, 2010).

2. Literature review to gather the domain knowledge needed to build a correct model (Dlamani, 2010 ; Ma et al. 2007).

3. Consultation with experts to identify the network's variables, and to elicit and assess the reliability of the CPTs associated to them (Newton, 2010)

4.Implementation of an optimisation algorithm to generate the necessary CPT, (Dlamani, 2010). 
The next sections summarise our modelling approach. A key point to note is that most of the variables in the network are continuous. We were able to handle this through using a network development environment that supported the use of continuous variables whose CPTs are expressed as arithmetic functions.

\subsubsection{Causal Factor Elicitation}

We started the elicitation of the variables for the model by referring to the standards that are available to different types of industry and economic sectors (BS ISO 14064:1-3, 2006; BS-EN-ISO 14044, 2006; PAS 2050:2008, 2008; IPCC, 2006), GHG-Protocol (WRI, 2010). Each one describes the set of procedures that a particular business must deploy to determine its "carbon footprint". Of these, the IPCC guidelines (IPCC, 2006) are the most relevant as they specifically address the issues linked to Agriculture and Land Use; indeed, they constitute the "de facto" standard for this particular economic sector.

The IPCC guidelines include the set of equations under-pinning the estimation of GHG emissions. In addition to the equations, two types of information are needed to carry out the computations; agricultural data, and emission factors. These last correspond to the ratio between the amount of pollution, i.e. GHG generated, and the amount of a given raw material processed that produced the polluting gas. For example, there will be an emission factor representing the amount of nitrogen emitted as a result of the quantity of nitrogen-based fertiliser applied to a hectare of cropland. In certain cases, the ratio is estimated using the emissions generated and the outputs of the production processes associated to those emissions (GES 1997). In this study, the pollutants correspond to GHG, specifically carbon dioxide $\left(\mathrm{CO}_{2}\right)$, nitrous oxide $\left(\mathrm{N}_{2} \mathrm{O}\right)$, and methane $\left(\mathrm{CH}_{4}\right)$. Given the complex chemical and biophysical interactions taking place, and the operational context, their estimation is highly uncertain. Consequently, we drew on a range of different approaches in order to ensure our models were as robust as possible. These included:

1. Review of publications describing the results of studies carried out to determine the emission factors associated to different agricultural activities, e.g. management of livestock, woodland management, manure management systems used, etc.

2. Use of standard brainstorming techniques with process experts to elicit all the potential input factors driving a particular aspect related to the farm's emissions or the effectiveness of the carbon sink under consideration. 
3. Use of conventional statistical analysis techniques to process the UK's agricultural sector data, which is recorded in various repositories and reports available to the public (DEFRA-AUK, 2008; NE, 2010; CLA, 2010).

It is possible that we could make further refinements that are informed by other models, such as CERES-EGC (Rolland et al., 2008), in the future.

Once all the necessary information has been processed, each variable is assigned a data type (categorical, discrete, continuous) and a scale. Then the causal relationships between variables are defined using the equations that appear in the IPCC guidelines for GHG estimation (IPCC, 2006) in the following manner:

- Identify the set of equations in the IPCC guidelines used for the estimation of the GHG emissions that result from the agricultural activity that is to be modelled. There are different equations in each case and Table A.1 in Appendix A lists the equations that were used in our model.

- Any equation includes two types of variables: an emission factor; or, activity data relating to the emission source (can be area, animal numbers or mass unit, depending on the source type). Both types can be input nodes in any of the sub-networks. The prior distributions for either of them are computed in the following manner:

a. The distributions of the activity data were obtained from the publicly available repositories on which records of the UK agricultural sector are held (DEFRA-AUK, 2008; NE, 2010; CLA, 2010).

b. The distributions of the emission factors were computed using the appropriate tables available in the IPCC guidelines. For most cases, the table includes the average value of the factor together with the level of uncertainty associated to the factor's estimation. This information is mapped to a normal distribution; an acceptable default model for any random variable in the absence of better information (central limit theorem).

c. Given that the calculations are aligned with the tier 1 method of the IPCC guidelines, there are default values for all the emission factors used in the various equations. For those cases in which there is no information regarding the level of uncertainty associated to the factor, the same is specified as a constant in the appropriate node in this version of the model.

- Most of the variables used in the IPCC guidelines' equations are continuous. As a result, in order to optimise the performance of the modelling tool we used, it is advisable that any intermediate or output node in the model does not have more than two parents. This rule was applied throughout, and the distributions of the intermediate 
nodes are specified as IPCC equations in all cases. The final network architecture was built following a progressive and iterative approach that processes each of the equations that need to be used, and increases the number of intermediate nodes until all the terms in the equation have been accounted for.

\subsubsection{Quantification of relationships}

The difficulty of building a BN model, which includes for the most part continuous nodes, was partly addressed through the choice of network development tool. AgenaRisk is a BN development environment (AgenaRisk, 2010) incorporating a flexible way of modelling continuous nodes. The tool's algorithm combines dynamic discretisation with robust propagation on junction tree structures. Dynamic discretisation is a computational mechanism that approximates the distribution of a continuous variable $\mathrm{X}$ by finding an optimal discrete set of intervals in the range of $\mathrm{X}$, and optimal values for X's discretised probability density function. Details of the approach are not needed in order to follow the rest of this paper, but can be found in (Neil et al. 2007, 2010). The junction tree structures enable the propagation of information, whilst at the same time avoiding the search space explosion that has hampered many past implementations of this kind.

This AgenaRisk feature enables the generation of CPTs for arithmetic expressions using "interval arithmetic", and together with the IPCC guidelines equations constitute the main enablers of the construction process followed to develop the intermediate and end nodes of the BN model for GHG estimation. Interval arithmetic is a mechanism for generating the posterior distribution of nodes whose CPT is expressed as a continuous function. It entails transforming the node's function into a piecewise set of constant values and/or functions, which are supported during the dynamic discretisation, and can be used to propagate information in a network with discrete and continuous nodes. For an arithmetic calculation, the relevant sub-domains are inserted for each constant/function at the start of the discretisation process and then the algorithm is initiated. The sub-domains will be maintained, unless a constant or function is assigned zero probability during an evidence propagation, in which case the relevant sub-domain is removed from the node's domain. Only those sub-domains with non-zero probability will be represented in the posterior marginal distribution for the node at the end of the process. Further details can be found in (Neil et al., 2010). 


\subsection{Estimation of a farm's annual GHG inventory using IPCC guidelines}

To measure the GHG emissions of a farm, it is necessary to assess the different activities affecting the farm's soilplant-animal components, and also the land area the farm is responsible for (Smith et al. 2008a, 2008b). In the particular case of the UK agricultural sector, those activities that contribute negatively and/or positively to the farm's emissions are:

- The number and type of livestock bred on the farm and the fate of their manure. Additionally, on farms without livestock, use of manure as fertiliser will be a contributing activity to emissions.

- The type of manure management system used on the farm.

- The crops grown on the land, and the crop management practices followed to grow those crops.

- The land area associated to the farm, and the use it is put to. The IPCC guidelines identify six types: cropland; grassland; forestland; wetland; settlement; or, other. In the UK agricultural sector the information available on land use only comprises the first three, i.e. cropland, grassland, forestland. These were the categories covered in the BN model developed.

- The energy consumed to carry out the different farm's activities. The three types of consumption covered in this model are: fuel to run the tractors and other vehicles; energy for heating; energy for electricity. The last two constitute indirect emissions, at least for those farmers who purchase their quota from external energy suppliers and do not produce their own energy. In this case, the "emitters" are really the energy suppliers, and not the farmer, and are thereby labelled "indirect emissions" in compliance with the existing standards, for example GHG-Protocol (WRI, 2010).

- Activities created to comply with the requirements outlined in different subsidy schemes designed to incentivise the farming community in the UK to take care of the wildlife and the countryside, for example planting and maintenance of hedgerows and shelterbelts. This type of activity is indirectly modelled through the land use and land management information.

The IPCC guidelines (IPCC, 2006) for the estimation of the GHG emissions produced by any economic sector have to use simple, readily available data (such as farm's animal numbers, fertiliser additions) in the calculations, since they are used all over the world to meet the United Nations Framework Convention on Climate Change (UNFCCC) reporting requirements (Smith et al., 2008a, 2008b). 
For agriculture, the guidelines provide methods to account for the non- $\mathrm{CO}_{2} \mathrm{GHG}$ emissions $\left(\mathrm{N}_{2} \mathrm{O}\right.$ and $\left.\mathrm{CH}_{4}\right)$, and in a separate section (on land use, land-use change and forestry; LULUCF), to account for $\mathrm{CO}_{2}$ emissions resulting from loss (or gains) in soil organic carbon (SOC). The non- $\mathrm{CO}_{2}$ GHG emissions are calculated using emission factors that are based on data such as the amount of nitrogen fertiliser applied, or the number of livestock of different species kept on the farm. The estimates of soil organic matter to $\mathrm{CO}_{2}$ ratios are based on changes in land use and changes in intensity of management and tillage, broken down by the IPCC land type categories (IPCC 2006). The estimation method is underpinned by a three-tiered approach. The guidelines include the equations and default parameters for tier 1 , the default and simplest approach. Tiers 2 and 3 require more accurate data, and are aimed at improving the accuracy and uncertainty of the calculations. This makes them more complex and resource intensive, therefore they are harder to apply. The network model built in this study is based on the tier 1 approach for the following reasons: (i) the data processed to estimate the prior distributions included in the BN model were obtained from publicly available repositories representing a population with a high level of variance, (ii) most of the emission factors used are the default values published in the IPCC guidelines, (iii) as a first attempt at applying the BN framework to this type of application, it constitutes a valid proposition. The equations used to compute the nodes' distributions are the ones listed in Appendix A, all of which were obtained from Volume 4 (IPCC 2006). 


\subsection{High-level Network Architecture}

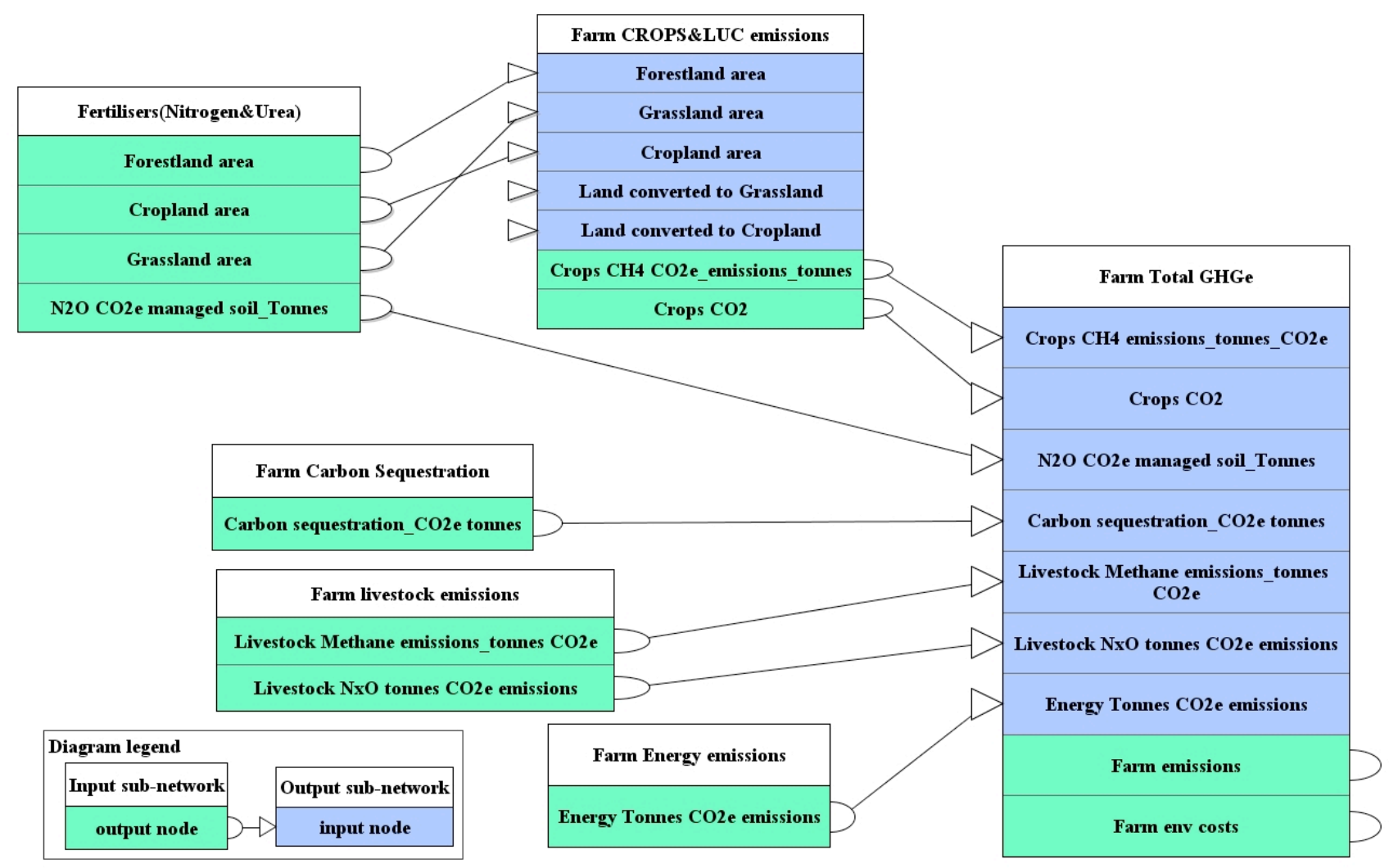

Figure 1 GHG Bayesian Belief Network - high-level network architecture. Each rectangle is a sub-network.

Blue labels: inputs to the sub-network. Green labels: outputs estimated by the sub-network. Directed links describe the flow of information in the model

A high level view of the network's architecture is shown in Figure 1. Each sub-network is responsible for the generation of a specific set of outputs. A directed link between two boxes indicates that the sub-network's output (green label) attached to the out-going end of the link will be fed to the input node (blue label) associated to the in-coming end of the link in the other sub-network when information is propagated through it (see legend on bottom left-hand corner of Figure 1). The overall architecture attempts to reflect the generic farm's processes that contribute negatively and/or positively to the farm's GHG fluxes in the following way:

1. Forestland management/harvested wood products: trees constitute an important carbon repository. The same applies to well-managed soil. The correct management of these two "natural" carbon sinks can be used to the farm's advantage to reduce the farm's overall carbon footprint. These emissions are estimated in the Farm Carbon Sequestration sub-network shown in Figure 1. 
2. Fertiliser use: the application of nitrogen-based fertilisers is common practice to increase the yield per hectare of farmed land. This practice can have serious environmental impacts, one of which corresponds to the $\mathrm{N}_{2} \mathrm{O}$ emissions resulting from the chemical processes that take place after the fertiliser has been applied to the land. In the network architecture (Figure 1) the sub-network that estimates these emissions is Fertilisers(Nitrogen\&Urea). The output generated is measured as CO2e units, and is fed to the Farm Total GHGe sub-network.

3. Crops and Land Use Change: the type of use given to a land area, and the type of crop grown have a considerable impact on the emissions resulting from the bio-physical processes that occur on that land. The GHG fluxes will be severely affected if there is a change to the manner in which the land is used. For example, the clearance of a piece of woodland to grow wheat will result in an important loss of carbon as a result of all the trees that were cut down. In the IPCC guidelines, the calculations that compute land use emissions are grouped in two categories: emissions from land use remaining unchanged, and emissions from land use conversion. Land use change, handling of crops, handling of orchards and other types of plantation, overall land management are the processes covered in this group. The emissions for this aspect of the farm are estimated in the Farm Crops\&LUC emissions sub-network. In all cases, the outputs generated are measured as CO2e units, and the output is fed to the Farm Total GHGe sub-network.

4. Livestock: a farm's livestock contributes to the farm's GHG fluxes in two different ways; the animals themselves as a result of being reared on the farm, and through a manure management system which can include manure from animals which don't have to be reared on the farm. In compliance with the IPCC guidelines (IPCC, 2006), the emissions are of two types; methane $\left(\mathrm{CH}_{4}\right)$ and nitrous oxide $\left(\mathrm{N}_{2} \mathrm{O}\right)$. In Figure 1, the component subnetwork that performs this set of calculations corresponds to Farm Livestock and generates the following outputs; tonnes of $\mathrm{CH}_{4}$, and tonnes of $\mathrm{N}_{2} \mathrm{O}$, measured as $\mathrm{CO} 2 \mathrm{e}$ units. Both outputs are then fed to the Farm Total $G H G e$, the sub-network designed to collate all the results. To transform the tonnes of a non- $\mathrm{CO}_{2}$ gas into $\mathrm{CO} 2 \mathrm{e}$ units, it is necessary to multiply the amount of gas by the appropriate Global Warming Potential (GWP), i.e. the ratio of heat trapped by one unit mass of the GHG to that of one unit mass of $\mathrm{CO}_{2}$ over a specified time period (IPCC, 2006). The GWP for the three main GHGs associated with farming over a 100 year time span, that are covered in this model are: $\mathrm{CO}_{2}=1 ; \mathrm{CH}_{4}=25 ; \mathrm{N}_{2} \mathrm{O}=298$ (Forster et al., 2007). 
5. Energy consumption: in a farm, like in any other business, energy is an essential component to conduct many of the tasks that are carried out. Electricity, gas for heating, and fuel to run the vehicles used on the farm make the bulk of the energy used. Some farms might have installed a renewable energy system on their land, to reduce costs and their carbon footprint. The emissions that result from this aspect of a farm's operations are computed using the Farm Energy emissions sub-network. The output is measured in $\mathrm{CO} 2 \mathrm{e}$ units.

The Farm Total GHGe sub-network in Figure 1 is the component in which the emissions estimated with the other subnetworks are collated to produce the final estimate of the farm's annual GHG emissions, or carbon footprint. In addition to the total emissions measured as tonnes of $\mathrm{CO} 2 \mathrm{e}$ units, this network estimates the farm's environmental costs in terms of the Shadow Price of Carbon (SPC), which is expressed as pounds sterling (£). The farm's emissions, expressed in monetary terms, can then be integrated to the rest of the farm's financial data, and by applying cost/benefit analysis it is possible to work out the most appropriate way, to reduce the farm's emissions without having a detrimental effect on the farm's return on investment.

The model development procedure described earlier was followed to develop all the model's sub-networks. The next section provides an outline of each of them.

\subsection{Component sub-networks}

Details of each of the sub-networks used in the model are provided in either tabular or graphical format. In each case, the information included corresponds to: input and output nodes; reference to the IPCC equations used to estimate the relevant GHG emissions; and data repositories accessed to compute the distributions of the network's input nodes. Details of the probability distributions of all the input/output nodes used in the various sub-networks are presented in Appendix B (Table B.1, Table B.2).

\subsubsection{Farm Livestock emissions sub-network}

\begin{tabular}{|l|l|l|}
\hline Node name & $\begin{array}{l}\text { Node type (discrete, } \\
\text { integer, continuous)/ } \\
\text { (input, intermediate, } \\
\text { output) }\end{array}$ & Distribution estimation procedure used \\
\hline $\begin{array}{l}\text { Dairy herd; other cattle; } \\
\text { sheep; pigs; goats; }\end{array}$ & $\begin{array}{l}\text { All the nodes are integer } \\
\text { input nodes }\end{array}$ & $\begin{array}{l}\text { Records of the number of animals of each type } \\
\text { reared on a UK farm are available from DEFRA }\end{array}$ \\
\hline
\end{tabular}




\begin{tabular}{|c|c|c|}
\hline $\begin{array}{l}\text { horses; poultry; other } \\
\text { birds }\end{array}$ & & $\begin{array}{l}\text { (2011). The records go back a number of years } \\
\text { (1970s onwards). The total number of animals } \\
\text { reared on a particular year can be divided by the } \\
\text { number of farms that reared that type of animal } \\
\text { (information also available in the repository). The } \\
\text { set is used to compute the mean and variance of an } \\
\text { initial default normal distribution for the node. }\end{array}$ \\
\hline $\begin{array}{l}\mathrm{CH}_{4} \text { Emissions from } \\
\text { herd's enteric } \\
\text { fermentation (one per } \\
\text { herd type (ht)) }\end{array}$ & $\begin{array}{l}\text { For each ht, an } \\
\text { intermediate continuous } \\
\text { node computes the } \mathrm{CH}_{4} \\
\text { emissions }\end{array}$ & $\begin{array}{l}\text { IPCC } 2006 \text {, volume } 4 \text {, chapter } 10 \text { (equations } 10.19 \text {, } \\
\text { 10.20). The emission factors needed in most cases } \\
\text { are defined as node's constants or as an input } \\
\text { continuous node with a normal distribution using } \\
\text { mean and variance from IPCC guidelines or } \\
\text { reviewed literature. }\end{array}$ \\
\hline $\begin{array}{l}\mathrm{CH}_{4} \text { Emissions from } \\
\text { herd's manure } \\
\text { management one per } \\
\text { (herd type, manure } \\
\text { management system) } \\
\text { (ht,mms) pair }\end{array}$ & $\begin{array}{l}\text { For each }(\mathrm{ht}, \mathrm{mms}) \text { pair } \\
\text { an intermediate } \\
\text { continuous node } \\
\text { computes the } \mathrm{CH}_{4} \\
\text { emissions }\end{array}$ & $\begin{array}{l}\text { IPCC } 2006 \text {, volume } 4 \text {, chapter } 10 \text { (equations } 10.19 \text {, } \\
10.20,10.22 \text { ). The emission factors needed in most } \\
\text { cases are defined as node's constants or as an input } \\
\text { continuous node with a normal distribution using } \\
\text { mean and variance from IPCC guidelines or } \\
\text { reviewed literature. }\end{array}$ \\
\hline $\begin{array}{l}\mathrm{N}_{2} \mathrm{O} \text { emissions from } \\
\text { herds' manure } \\
\text { management system } \\
(\mathrm{mms}, \mathrm{ht})\end{array}$ & $\begin{array}{l}\text { For each pair }(\mathrm{mms}, \mathrm{ht}) \\
\text { an intermediate } \\
\text { continuous node } \\
\text { computes the } \mathrm{N}_{2} \mathrm{O} \\
\text { emissions }\end{array}$ & $\begin{array}{l}\text { IPCC } 2006 \text {, volume } 4 \text {, chapter } 11 \text { (equations } 11.1 \text { ). } \\
\text { The emission factors needed in most cases are } \\
\text { defined as node's constants or as an input } \\
\text { continuous node with a normal distribution using } \\
\text { mean and variance from IPCC guidelines or } \\
\text { reviewed literature. }\end{array}$ \\
\hline $\begin{array}{l}\mathrm{N}_{2} \mathrm{O} \text { indirect emissions } \\
\text { from } \mathrm{MM}(\mathrm{mms}, \mathrm{ht})\end{array}$ & $\begin{array}{l}\text { For each pair (mms,ht) } \\
\text { an intermediate } \\
\text { continuous node } \\
\text { computes the } \mathrm{N}_{2} \mathrm{O} \\
\text { indirect emissions }\end{array}$ & $\begin{array}{l}\text { IPCC } 2006 \text {, volume } 4 \text {, chapter } 10 \text { (equations } 10.26 \text {, } \\
10.27 \text { ). The emission factors needed in most cases } \\
\text { are defined as node's constants or as an input } \\
\text { continuous node with a normal distribution using } \\
\text { mean and variance from IPCC guidelines or } \\
\text { reviewed literature. } \mathrm{N}_{2} \mathrm{O} \text { emissions from leaching } \\
\text { and nitrogen volatilisation. }\end{array}$ \\
\hline $\begin{array}{l}\text { Livestock } \mathrm{CH}_{4} \text { enteric } \\
\text { fermentation }\end{array}$ & $\begin{array}{l}\text { Intermediate continuous } \\
\text { node }\end{array}$ & $\begin{array}{l}\text { Estimates the farm's } \mathrm{CH}_{4} \text { emissions from enteric } \\
\text { fermentation by adding up the } \mathrm{CH}_{4} \text { emissions from } \\
\text { each herd type. The node's distribution is computed } \\
\text { using interval arithmetic. }\end{array}$ \\
\hline $\begin{array}{l}\mathrm{CH}_{4} \text { manure } \\
\text { management }\end{array}$ & $\begin{array}{l}\text { Intermediate continuous } \\
\text { node }\end{array}$ & $\begin{array}{l}\text { Estimates the farm's } \mathrm{CH}_{4} \text { emissions from the } \\
\text { different (mms, ht) pairs by adding up the } \mathrm{CH}_{4} \\
\text { emissions from each pair. The node's distribution is } \\
\text { computed using interval arithmetic. }\end{array}$ \\
\hline $\begin{array}{l}\text { Livestock Methane } \\
\text { emissions_tonnes } \mathrm{CO} 2 \mathrm{e}\end{array}$ & Output continuous node & $\begin{array}{l}\text { Estimates the total farm's } \mathrm{CH}_{4} \text { emissions produced } \\
\text { by adding, the } \mathrm{CH}_{4} \text { from the (mms, ht) used, and the } \\
\mathrm{CH}_{4} \text { produced by the herd reared on the farm. The } \\
\text { distribution is computed using interval arithmetic. }\end{array}$ \\
\hline $\begin{array}{l}\text { Farm annual indirect } \\
\mathrm{N}_{2} \mathrm{O} \text { emissions from }\end{array}$ & $\begin{array}{l}\text { Intermediate continuous } \\
\text { node }\end{array}$ & $\begin{array}{l}\text { Estimates the total indirect } \mathrm{N}_{2} \mathrm{O} \text { emissions from the } \\
\text { different }(\mathrm{mm}, \mathrm{ht}) \text { pairs on the farm by adding up the }\end{array}$ \\
\hline
\end{tabular}




\begin{tabular}{|l|l|l|}
\hline (mm,ht) & $\begin{array}{l}\text { indirect } \mathrm{N}_{2} \mathrm{O} \text { computed for each one. The node's } \\
\text { distribution is computed using interval arithmetic. }\end{array}$ \\
\hline $\begin{array}{l}\text { Livestock } \mathrm{N}_{2} \mathrm{O} \text { tonnes } \\
\mathrm{CO} 2 \mathrm{e} \text { emissions }\end{array}$ & Output continuous node & $\begin{array}{l}\text { It estimates the total farm's } \mathrm{N}_{2} \mathrm{O} \text { emissions by } \\
\text { adding the } \mathrm{N}_{2} \mathrm{O} \text { emissions that result from the herds, } \\
\text { and the different (mms, ht) in use. The distribution } \\
\text { is computed using interval arithmetic. }\end{array}$ \\
\hline
\end{tabular}

Table 1 Summary of the farm livestock emissions sub-network. Each row in the table corresponds to one or more nodes. The first column provides the name(s) of the node. The second column identifies whether the respective nodes are input, output or intermediate nodes, and their scale type (integer, discrete, continuous or ranked). The third column summarises the procedure used for estimating the probability distributions for the prior (for input nodes) or conditional (for intermediate or output nodes) probability tables. Note that a node in the graphical model represents a variable in the corresponding probabilistic model.

The main input, output and intermediate nodes of the farm's livestock sub-network are described in (Table 1). The types of herd covered in this case correspond to the most common types of animal found on a British farm: cattle, sheep, pigs, poultry, goats, and horses. The types of manure management systems are: liquid slurry; daily spread; solid 'deep litter' storage; and, pasture range and paddock. Information about the systems was obtained from DEFRA's report on fertiliser practice in the UK (DEFRA-BSFP, 2009). In this sub-network the emissions of two types of GHG are estimated: methane $\left(\mathrm{CH}_{4}\right)$ and nitrous oxide $\left(\mathrm{N}_{2} \mathrm{O}\right)$. 


\subsubsection{Farm Use of Fertilisers, Crops\&Land Use Change Emissions sub-network}

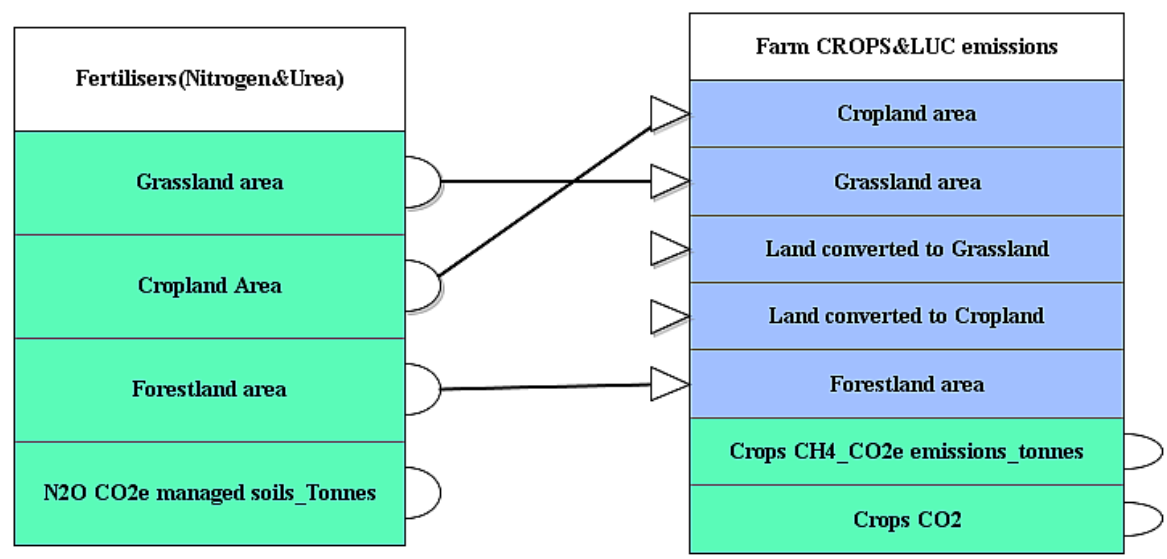

Figure 2 Fertilisers (Nitrogen\&Urea), Farm crops \& LUC emissions sub-networks. Outputs: N2O CO2e managed soils_Tonnes, Crops CH4_CO2e emissions_tonnes, Crops CO2e

The diagram in Figure 2 shows the high level architecture of this sub-network. It includes two component subnetworks. The information of the principal input/output nodes and equations used in them are described in Table 2 . The network structure shows how the land use information is shared between the two sub-networks. Details of the probability distributions for the input/output nodes are included in Appendix B (Table B.1, Table B.2).

\begin{tabular}{|l|l|l|}
\hline Node name & $\begin{array}{l}\text { Node type (discrete, integer, } \\
\text { continuous)/ (input, } \\
\text { intermediate, output) }\end{array}$ & \multicolumn{1}{c|}{ Distribution estimation procedure used } \\
\hline $\begin{array}{l}\text { Cropland area, } \\
\text { Grassland area, } \\
\text { Forestland area } \\
\text { All are continuous input } \\
\text { nodes. }\end{array}$ & $\begin{array}{l}\text { Records of the area and land use in the UK agricultural } \\
\text { sector are available at DEFRA (2011). The records go back a } \\
\text { number of years (1970s onwards). The total area in hectares } \\
\text { on a particular year can be divided by the number of farms } \\
\text { recorded on that year (information also available in the } \\
\text { repository). The set is used to compute the mean and variance } \\
\text { of an initial default normal distribution for each land use type } \\
\text { node. }\end{array}$ \\
\hline $\begin{array}{l}\text { Land converted to } \\
\text { cropland, Land } \\
\text { converted to } \\
\text { grassland, Land } \\
\text { converted to forest } \\
\text { land }\end{array}$ & $\begin{array}{l}\text { All the nodes are continuous } \\
\text { input nodes. }\end{array}$ & $\begin{array}{l}\text { Land use changes are from DEFRA (2011), and the Land } \\
\text { use change matrix for the UK agriculture sector calculated by } \\
\text { these input nodes are computed assuming a uniform spread of } \\
\text { the changes across all the farms in the UK, which for a } \\
\text { default scenario is a reasonable estimate }\end{array}$ \\
\hline $\begin{array}{l}\text { Annual change in } \\
\text { carbon stocks for } \\
\text { a Land use } \\
\text { remaining } \\
\text { unchanged }\end{array}$ & $\begin{array}{l}\text { For each land use type there is } \\
\text { one such intermediate } \\
\text { continuous node. }\end{array}$ & $\begin{array}{l}\text { IPCC 2006, volume 4, chapters 2, } \\
\text { For Cropland remaining cropland (equations 2.7, 2.25, 2.26) } \\
\text { For Grassland remaining Grassland (equations 2.25, 2.26) } \\
\text { For Forestland remaining Forestland (equations 2.9, 2.10, } \\
\text { 2.11, 2,12, 2,13) }\end{array}$ \\
\hline
\end{tabular}




\begin{tabular}{|l|l|l|}
\hline & & $\begin{array}{l}\text { The emission factors needed in all cases are defined as node's } \\
\text { constants. Each node's distribution is computed using interval } \\
\text { arithmetic }\end{array}$ \\
\hline $\begin{array}{l}\text { AncC 2006, volume 4, chapter 2 } \\
\text { carbon stocks } \\
\text { resulting from } \\
\text { land use change } \\
\text { Land converted to forestland (equations 2.9, 2.10, 2.13, 2.14, } \\
2.23) \\
\text { Land converted to grassland (equations 2.15, 2.16, 2.23, 2.25) } \\
\text { Land converted to cropland (2.15, 2.16) } \\
\text { The emission factors needed in all cases are defined as node's } \\
\text { intermediate node computes } \\
\text { the change in carbon stocks. } \\
\text { constants obtained from the IPCC guidelines tables or from } \\
\text { literature reviews, }\end{array}$ \\
$\begin{array}{l}\text { Nodes computing } \\
\text { nitrogen emissions } \\
\text { from liming and } \\
\text { the application of } \\
\text { urea }\end{array}$ & $\begin{array}{l}\text { There is one intermediate } \\
\text { continuous node for estimating } \\
\text { these emissions for each land } \\
\text { use type. }\end{array}$ & $\begin{array}{l}\text { IPCC 2006, volume 4, chapter 11 } \\
\text { Liming (equations 11.13). } \\
\text { Urea (equations 11.12) } \\
\text { The application rate of this type of fertilisers is obtained from } \\
\text { the UK annual guide on fertiliser application. }\end{array}$ \\
\hline
\end{tabular}

Table 2: Nodes and distribution estimation procedure for the Farm use of fertilisers and land use change subnetwork. The columns follow the same structure as Table 1.

The Fertilisers-(Nitrogen\&Urea) sub-network estimates the emissions generated through the use of fertilisers on the farm. The emissions produced through the other land management activities are computed in the Farm crops\&LUC emissions sub-component. The outputs of both sub-components are added together to compute the final estimates on GHG emissions associated with this farming activity $\left(\mathrm{N}_{2} \mathrm{O} \mathrm{CO} 2 \mathrm{e}\right.$ managed soils_tonnes CO2e, Crops CH4_CO2e emissions_tonnes_CO2e,Crops CO2 tonnes_CO2e). All these output nodes are continuous and their distributions were generated using interval arithmetic. The network's inputs can be assigned values through the propagation of information from one sub-network to another (Grassland area, Cropland area in Figure 2), or they can be specifically set by the user of the model (Land converted to Cropland, Land converted to Grassland in Figure 2).

The changes in carbon stocks from land use change have the highest level of uncertainty because there was little information available to create the default distributions, and the IPCC equations use a high number of emission factors, most of which were set to the default values available in the IPCC guidelines. A further contributing problem lies in the fact that there is little information at country level relating land use to the type of land management techniques applied to that land. This makes the type of default emission factors used even more unreliable. 
Three types of GHG are produced through the farm activities covered in these sub-networks: $\mathrm{CO}_{2}$ (output Crops $\mathrm{CO} 2 \mathrm{e}$ ), $\mathrm{N}_{2} \mathrm{O}$ (output $\mathrm{N} 2 \mathrm{O} \mathrm{CO} 2 \mathrm{e}$ managed soils_Tonnes), and $\mathrm{CH}_{4}$ (output Crops $\mathrm{CH} 4$ _CO2e emissions_tonnes).

\subsubsection{Farm Energy emissions}



Figure 3 sub-network Farm energy emissions. Input nodes: Electricity, Gas, Diesel, are all drawn as rectangles

to show the evidence on energy consumption rates for each scenario. Output node: Farm Energy emissions, it is drawn as a rectangle to show the distributions for each of the three scenarios fed to the network. There is one coloured distribution for each one: orange low grazing-ms; purple mixed; green dairy

This sub-network (Figure 3) computes the emissions, measured as tonnes of CO2e, generated through the energy consumed on the farm. The types of energy use covered are: heating, electricity, and transport. Table A.1 in Appendix A includes details of the set of equations used to compute the intermediate and output nodes of this sub-network. The information on energy consumption was obtained from (Warwick-HRI, 2007). The emission factors used in the intermediate nodes were obtained from (DEFRA, DECC 2009).

The input node with a red label, i.e. "RE emissions", provides an initial estimate of the emissions that result from the consumption of energy generated with a renewable energy system. In this version of the model, given the very reduced amount of evidence there is on the use of such systems on a British farm, the calculations for the case study scenario 
were done manually and the final estimate fed directly to the system as one node with a prior distribution.

\subsubsection{Carbon Sequestration sub-network}

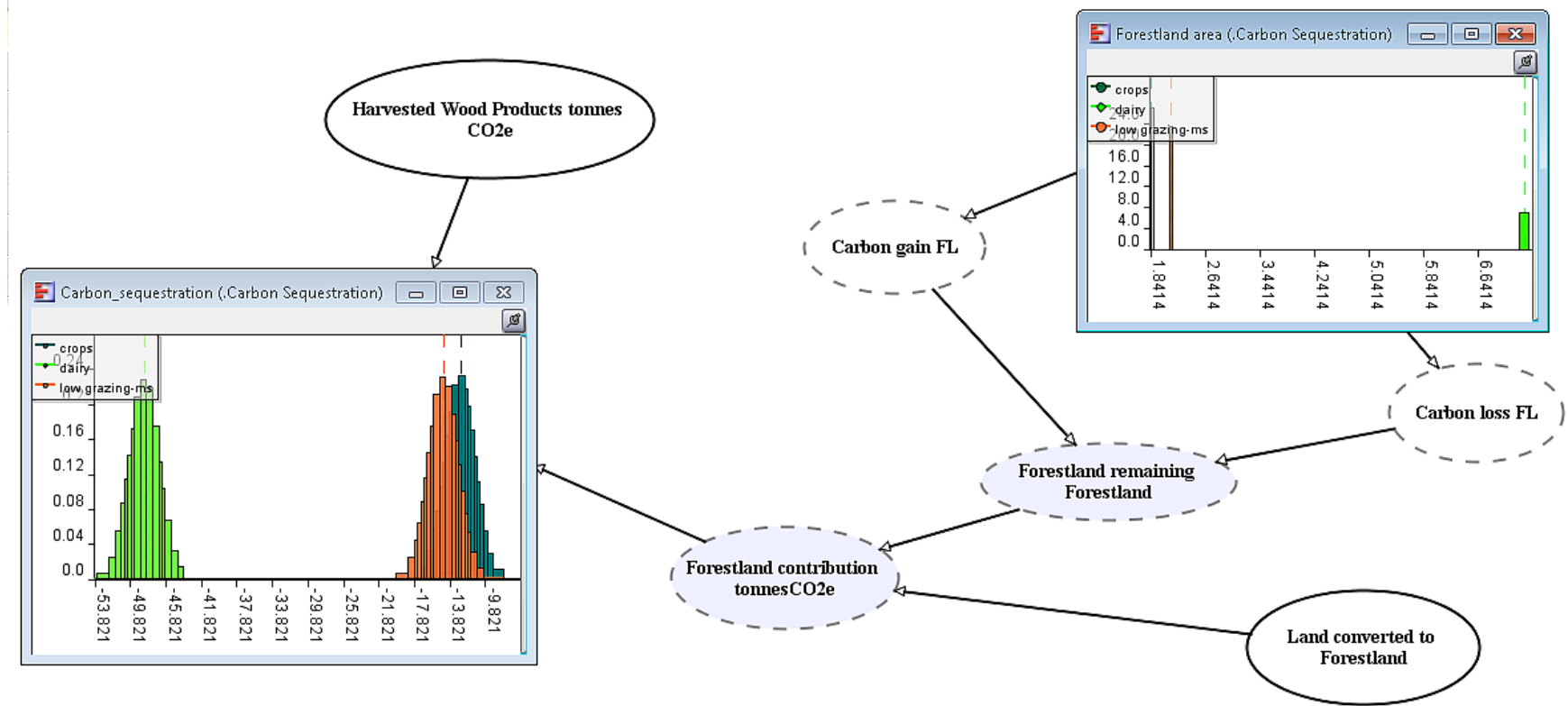

Figure 4 Carbon Sequestration sub-network. Greyed out nodes with dashed lines are intermediate nodes.

Output node: Carbon_sequestration, the node is drawn as a rectangle to show the distributions for each of the

three scenarios fed to the network. There is one coloured distribution for each one: (orange low grazing-ms; light green dairy; dark green crops)

The graph presented in Figure 4 shows the architecture of the sub-network built to estimate the reduction in carbon emissions achieved on the farm by the exploitation of its "natural" carbon sinks. The output node (Carbon_sequestration) shows three distributions, each corresponding to the emissions of three of the scenarios that were fed to the network.

The directed graph of the Farm total GHGe sub-network is shown in the worked example section, which describes the results of some of the scenarios employed to validate the network model.

\subsection{Evaluation Method}

Rigorous evaluation is difficult at the moment given the limited availability of ground-truth in this domain. However, we can compare the results from our model with the alternative model encapsulated in the CALM tool (CLA, 2010). This also provides us with the basis for a discussion of the benefits of our approach. This particular choice is based on the fact 
that CALM is the tool of choice for the Country Land and Business Association (CLA), therefore it is well known by a fairly large group of the farming community. CALM is an internet-based tool, and provides a standard interface to feed it with the information that it needs to estimate the farm's GHGe. It was necessary to create an instance for each of the scenarios used in our evaluation. For a particular farm, the tool displays a form in tabular format with a list of the information a user must provide about the farm. The table is divided in sections, one for each type of farm operation. The grouping is similar to the one used in the BN model, i.e. crops grown, livestock reared, fertiliser consumption, energy consumption, land use, and land use change. The farm's GHG emissions are estimated concurrently as information is fed through the form. The disadvantage of using a tool of this type is that it is not possible to investigate in detail the manner in which the tool's computations are carried out, and as there are no publications describing the process, it was not possible to include in the comparison this level of detail. We assume, however, that the tool provides a deterministic evaluation of the input data using the equations provided in the IPCC guidelines.

\section{Results}

This section illustrates the use of the model by means of case studies for several farm types. It also contains the results of our comparison with the CALM tool.

\subsection{Case Study input data}

There are several ways in which farms can be classified. Location or size may be appropriate for some kinds of studies. However, to ease the model construction, we used the same classification scheme as that applied to the farming data stored in the repositories from which most of the farming data used to calibrate the network model was sourced. These categories are:

1. Livestock farm: This can be further sub-divided in dairy, beef cattle, sheep, pigs, poultry, or any combination of the herds. A farm belongs to this category if its main source of income comes from the herd that it breeds.

2. Crops farm: This can be further subdivided on the type of crops it grows; a farm belongs to this category if it doesn't handle livestock and its main source of income comes from the crops it grows. Farms that grow cereals are also included in this group.

3. Mixed farm: Combines livestock and crops. Its income is fairly well subdivided between the two. 
4. Low grazing farm: The farming sector in the UK located in the lowlands constitutes a unique group with its particular set of problems due in part to the geography of the area. For this reason, it is considered a group apart from the others.

There are many on-going discussions regarding which of these types of farming is more environmentally friendly (from the GHG emissions perspective). Although there has been a relatively strong movement advocating for the reduction of livestock as this is one of the main contributors to the volume of $\mathrm{CH}_{4}$ emissions linked to the farming sector (ZCB 2010), it might not be as high as those generated by a crop farm carrying out intensive farming and using a high volume of nitrogen-based fertilisers; after all the $\mathrm{N}_{2} \mathrm{O}$ has a higher GWP than the $\mathrm{CH}_{4}$ itself (Forster et al. 2007). This is the main reason why the scenarios used to validate the $\mathrm{BN}$ model are structured in the manner presented in Table 3 .

The data in Table 3 shows the six hypothetical farm scenarios (columns 2-7) designed to build the case study. The data in each column is chosen to be representative of each farm type, based on the information available in the repositories that were accessed to build the model (DEFRA-AUK, 2008; Countryside Survey, 2008; CEH, 2008; UK-NAEI, 2008; CLA, 2010). The first column of the table lists the names of the data presented in the other cells. The first row includes the name of the scenarios that were built. The farm types covered are: crops; dairy; low grazing; mixed; mixed renewables. All of the categories, except for the renewables type, are covered in the DEFRA classification. The mixed renewables farm has the same profile as that of the mixed farm, the difference between them lies in the fact that one uses conventional energy sources for all its energy needs, whilst the other uses energy supplied through renewable sources to satisfy its heating and electrical requirements (but not the fuelling of its vehicles).

\begin{tabular}{|c|c|c|c|c|c|c|}
\hline $\begin{array}{l}\text { Farm type/ Farm } \\
\text { factors (units) }\end{array}$ & $\begin{array}{l}\text { Crops } \\
\text { farm }\end{array}$ & $\begin{array}{l}\text { Dairy } \\
\text { farm }\end{array}$ & $\begin{array}{l}\text { Low Grazing } \\
\text { farm }\end{array}$ & Mixed farm & \begin{tabular}{l}
\multicolumn{1}{c}{ Mixed } \\
renewables \\
farm
\end{tabular} & $\begin{array}{l}\text { Low Grazing-ms } \\
\text { farm }\end{array}$ \\
\hline $\begin{array}{c}\text { Grassland } \\
\text { (hectares) }\end{array}$ & 0.68 & 33.31 & 131.76 & 26.31 & 26.31 & 38.62 \\
\hline $\begin{array}{c}\text { Cropland } \\
\text { (hectares) }\end{array}$ & 38.31 & 0.22 & 0.30 & 7.22 & 7.22 & 0.09 \\
\hline $\begin{array}{l}\text { Forestland } \\
\text { (hectares) }\end{array}$ & 1.86 & 7.32 & 7.32 & 7.32 & 7.32 & 2.15 \\
\hline LUC (hectares) & 2.81 & 0.01 & 2.81 & 2.81 & 2.81 & 0.82 \\
\hline $\begin{array}{l}\text { Farm size (total } \\
\text { area - hectares) }\end{array}$ & 40.85 & 40.85 & 139.38 & 40.85 & 40.85 & 40.85 \\
\hline $\begin{array}{l}\text { Dairy herd } \\
\text { (heads) }\end{array}$ & & 100.00 & 20.00 & 20.00 & 20.00 & 5.86 \\
\hline Sheep (heads) & & 46.00 & 1464.00 & 156.00 & 156.00 & 429.07 \\
\hline $\begin{array}{l}\text { Fertilisers on } \\
\text { crops(tonnes total } \\
\text { applied*year-1) } \\
\end{array}$ & 5.66 & 0.03 & 0.04 & 1.07 & 1.07 & 0.01 \\
\hline $\begin{array}{c}\text { Fertilisers on } \\
\text { grass(tonnes total }\end{array}$ & 0.07 & 3.49 & 13.79 & 2.75 & 2.75 & 4.04 \\
\hline
\end{tabular}




\begin{tabular}{|c|c|c|c|c|c|c|}
\hline applied*year-1) & & & & & & \\
\hline $\begin{array}{l}\text { Urea (tonnes total } \\
\text { applied*year-1) }\end{array}$ & 1.15 & 0.14 & 1.18 & 1.29 & 1.29 & 0.35 \\
\hline $\begin{array}{l}\text { Lime products } \\
\text { (tonnes total } \\
\text { applied*year-1) }\end{array}$ & 1.60 & 1.50 & 5.80 & 1.20 & 1.20 & 1.70 \\
\hline $\begin{array}{l}\text { Liquid waste } \\
\text { (GHG Tonnes*year- } \\
\text { 1) }\end{array}$ & & 0.04 & 0.02 & 0.03 & 0.03 & 0.01 \\
\hline $\begin{array}{l}\text { Solid waste } \\
\text { (GHG Tonnes*year- } \\
\text { 1) }\end{array}$ & & -0.03 & 0.00 & 0.02 & 0.02 & 0.00 \\
\hline $\begin{array}{r}\text { Electricity use } \\
\text { (KWhrs*year-1) }\end{array}$ & 4725.17 & 4725.17 & 6110.04 & 3306.09 & 3306.09 & 3200.00 \\
\hline $\begin{array}{c}\text { Gas use } \\
\text { (KWhrs*year-1) }\end{array}$ & 30120.50 & 30120.50 & 38948.33 & 30120.50 & 30120.50 & 29500.00 \\
\hline $\begin{array}{c}\text { Fuel use } \\
\text { (litres*year-1) }\end{array}$ & 10125.20 & 10125.20 & 13092.73 & 10001.10 & 10001.10 & 3837.27 \\
\hline
\end{tabular}

Table 3 Farm profiles (inputs to $\mathrm{BN}$ model)

The choice of the scenarios presented was fairly straightforward. The selection of farm type is based on the most typical types currently found in the UK (DEFRA-AUK, 2008); these types of farm constitute almost $60 \%$ of the sector. The choice of farm size is based on the fact that approximately $75 \%$ of them are less than 50 hectares. Sheep and dairy cattle are the most common type of livestock, and farms of this type constitute approximately $31 \%$ of the sector. In order to control the variables used to compute the emissions, it was necessary to select farms of fairly similar sizes. However, the low grazing farm comprises a much larger area, in order to asses the effect of land size on the overall computation of the GHG emissions, when compared against the emissions produced by a farm with similar characteristics but of a smaller size (low grazing-ms farm). The dairy farm is of a similar size as that of the low grazing-ms farm, the crops farm, and the mixed farm; these cases were designed to evaluate the impact that different farm types have on the GHG estimation models. The mixed renewables farm case was included to gain a better idea of the improvements on emissions that can be achieved if a farm switches to renewable energy for certain operations. 


\subsection{Results of case studies}

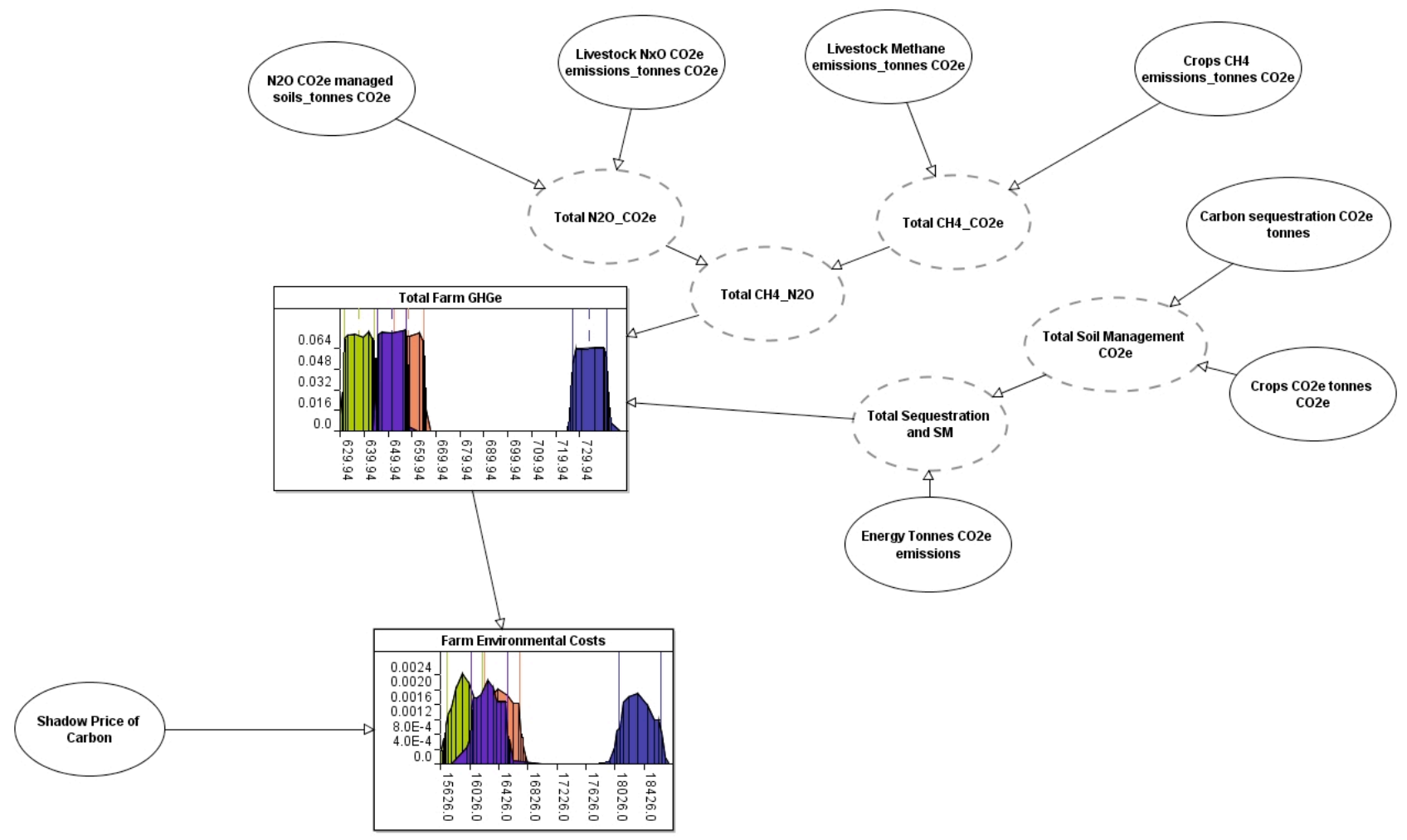

Figure 5 Farm Total GHGe sub-network (case study) (green: mixed renewable; purple: low grazing-ms; orange: mixed; blue: low grazing). Dashed line nodes are the network's intermediate nodes. Solid line nodes are network inputs. Rectangular nodes with distributions are the network's outputs

The Farm Total GHGe sub-network presented in Figure 5 shows the distributions of some of the scenarios listed in Table 3. The colour correspondence of the distributions displayed in the graph, and the scenarios described in Table 3 is listed in the figure's caption. The data associated to each of the input nodes has been computed by the other subnetworks, and is fed to the total network component in the final stage of the calculations. 


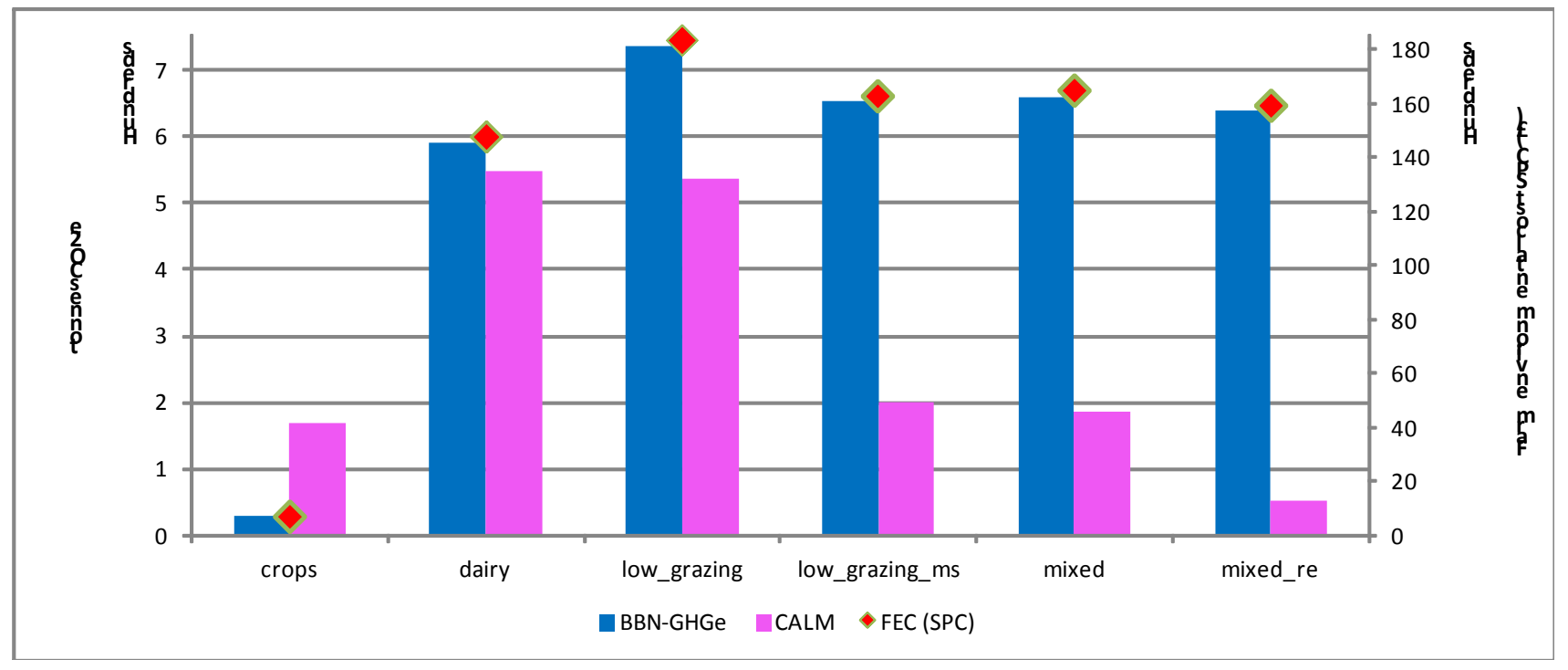

Figure 6 GHGe estimations results BN vs. CALM

The emissions for each of the scenarios described in Table 3 are displayed in Figure 6. It also includes the computations generated with the CALM tool for assessment purposes. Due to the significant differences between the emissions estimated in each scenario, it is not practical to include details of the credible intervals associated to each one. To this end, details of the distributions of the network outputs, i.e. the GHGe, for each scenario are included in Table 4. For each of the scenarios, the means, medians, standard deviations, and variances of the farm's GHGe estimated with the BN model are listed. The last two columns in the table provide the upper and lower percentile of the node's credible intervals. The information in Error! Reference source not found. illustrate that our model is providing quite tight distributions on the estimated values. However, it should be noted that: (a) we are not currently able to validate the absolute scales of the estimates; and (b), we have not factored in any uncertainty on the input values of the scenarios. This type of information is not generated with the CALM tool therefore it is not possible to compare the reliability of distributions estimated with each of the tools.

\begin{tabular}{|l|c|c|c|c|c|c|}
\hline Scenario Name & $\begin{array}{c}\text { Mean total } \\
\text { GHGe }\end{array}$ & $\begin{array}{c}\text { Median } \\
\text { total GHGe }\end{array}$ & $\begin{array}{l}\text { Standard } \\
\text { Deviation }\end{array}$ & Variance & $\begin{array}{l}\text { Lower } \\
\text { Percentile } \\
(\mathbf{5 \%})\end{array}$ & $\begin{array}{l}\text { Upper } \\
\text { Percentile } \\
(\mathbf{9 5 \%})\end{array}$ \\
\hline crops & 28.90 & 28.90 & 0.25 & 0.06 & 28.69 & 29.11 \\
\hline dairy & 590.51 & 590.49 & 3.52 & 12.40 & 587.444 & 593.60 \\
\hline low grazing & 734.16 & 734.18 & 4.36 & 19.04 & 730.24 & 738.09 \\
\hline
\end{tabular}




\begin{tabular}{|l|c|c|c|c|c|c|}
\hline mixed & 658.73 & 658.73 & 3.67 & 13.49 & 655.32 & 662.15 \\
\hline mixed-re & 638.00 & 637.97 & 3.88 & 15.05 & 634.60 & 641.45 \\
\hline low grazing-ms & 651.72 & 651.73 & 3.51 & 12.33 & 648.42 & 655.03 \\
\hline
\end{tabular}

Table 4 Mean, Median, Standard Deviation, Variance, Lower/Upper Percentiles for the GHGe estimates in the six scenarios.

The main outputs of the Farm Total GHGe sub-network, as mentioned earlier, correspond to the annual GHG emissions (tonnes CO2e, left axis in Figure 6) produced from each farm's operations, and the costs (expressed as SPC in $£$, right axis Figure 6) associated to this type of environmental impact. The data shows that the farm practice with the lowest environmental cost is the crops farm, which is in broad agreement with the results computed by the CALM tool. It also shows that the low grazing farm has the highest environmental cost which is not unreasonable given that it is the farm that manages the highest amount of land, uses nitrogen-based fertilisers, breeds livestock, and has a fairly small woodland, relative to its overall size, when compared against that of the other farm scenarios used in the case study. The effects on GHG emissions that result from changing the energy supply for the mixed farm to a renewable energy system $\left(6^{\text {th }}\right.$ column in Table 3$)$, does have an impact on the farm's emissions, although the magnitude of this differs significantly to that suggested by CALM. The potential economic implications associated with this kind of change demand alternative solutions to the problem of reducing the GHG emissions.

\begin{tabular}{|c|c|c|}
\hline Grand total (BN GHGe) & 58212.97 & -0.40 \\
\hline Grand total (CALM) & 108821.24 & -1.61 \\
\hline $\begin{array}{c}\text { GHG inventory (UKs } \\
\text { NAEI, 2008) }\end{array}$ & 41625.42 & - \\
\hline
\end{tabular}

Table 5 Mean, Median, Standard Deviations, Variance, Lower/Upper Percentiles for the FEC estimates in the six scenarios.)

Using the number and type of farms, it is possible to calculate a coarse estimate of the agricultural sector's emissions from the results obtained with the two tools. These values are presented in Table 5, and are compared against the emissions for the same sector recorded in the 2008 GHG inventory for the UK (Sneddon et al., 2010). The values in the table show that the $\mathrm{BN}$ estimates are closer to the inventory, and highlight the difficulties in reaching consensus on which are the most accurate results. The red points in Figure 6 shows the costs $(\mathfrak{f})$ of the GHG emitted by the farms. These are plotted against the axis on the right hand side. It is not possible at present to validate this calculation, as it is an estimate that is only computed by the $\mathrm{BN}$ described in this paper. 
In an attempt to find more financially viable ways of reducing the emissions in the mixed farm, and also to show a feature that is probably unique to this type of application, information was fed to the BN model using the GHG emissions node as input and then back-propagating the information through the network to the other components. The results generated with this computation appear in the chart of Figure 7 . They show that it is possible to achieve a $25 \%$ reduction of the emissions on the farm through a $27 \%$ reduction on the use of fertilisers, a $33 \%$ reduction on the emissions that result from livestock, a 33\% increase in the level of carbon sequestered through appropriate land management practices, and a $17 \%$ reduction on the emissions resulting from the farm's energy consumption. It shows that the farming sector can have a greater impact on its carbon footprint through appropriate land and livestock management practices, than through a reduction of its energy consumption or through replacing the current supply by an alternative energy type. Furthermore, these measures would probably have a smaller financial impact on the farm's budget than that of deploying a complete renewable energy system. This will vary in line with the financial incentives relating to energy use that the Government is offering at the time that the analysis is carried out, for example feed in tariffs, DECC (2011)

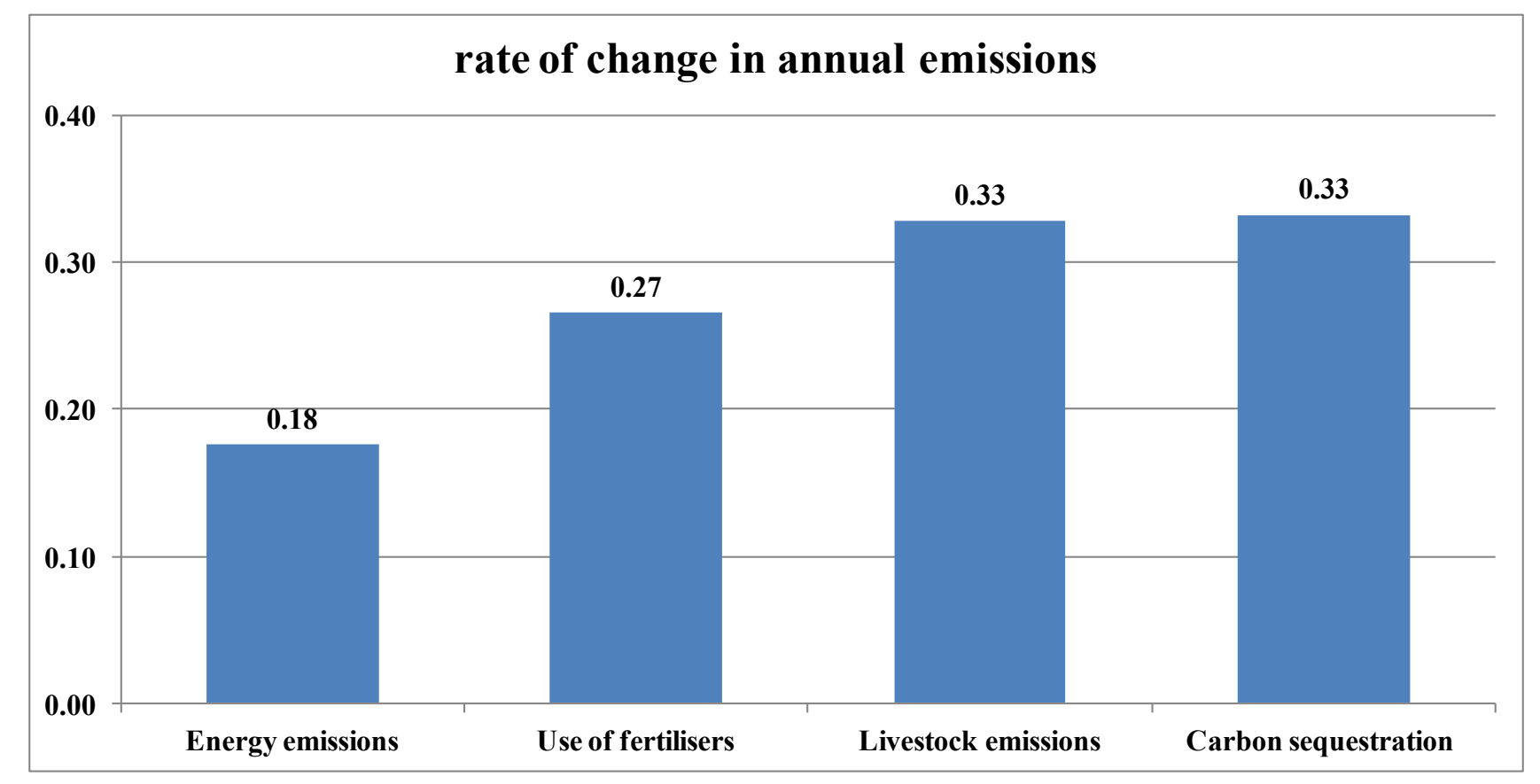

Figure 7 farm management changes required to reduce GHG emissions by $25 \%$ on mixed farm 


\section{Discussion}

\subsection{Comparison of the BN model with CALM}

The results in both tools are consistent with regards to which of them have the highest level of emissions and which have the lowest, nevertheless there are significant differences between the estimates calculated by each tool for each of the scenario covered in the case study. The following list hopefully goes some to way to explain these differences:

- The GWP factors used in each tool

○ $\operatorname{CALM}\left(\mathrm{CH}_{4}=21 ; \mathrm{N}_{2} \mathrm{O}=310\right)$

B $\quad$ aNGAS $\left(\mathrm{CH}_{4}=25 ; \mathrm{N}_{2} \mathrm{O}=298\right)$

- The CALM manual explains that the conversion factors it uses are those listed in the $2^{\text {nd }}$ Assessment Report by the IPCC (1995). These were later replaced in their methodology with the factors used in BaNGAS, but the change has not been incorporated into the CALM tool.

- $\quad$ CALM uses tier 2 equations to calculate $\mathrm{CH}_{4}$ emissions associated to livestock, BaNGAS uses tier 1, scope 1 calculations throughout.

- CALM uses tier 2, scope 2 equations to calculate direct and indirect $\mathrm{N}_{2} \mathrm{O}$ emissions.

- CALM and BaNGAS do not include the same types of Energy.

- $\quad$ CALM makes more effective use of the input on crops (e.g. crop residues)

- There are no details publicly available describing the emission factors used by CALM. These are needed to apply the equations described in the IPCC guidelines (IPCC 2006).

The discrepancies between the BN tool developed in the current study and CALM will require further investigation in the future, and even though it has not been possible to review the assumptions, or the calculation system used by the CALM tool, the differences are likely to result from: (i) the fact that the emissions appear to be computed using a combination of Tier 1 and Tier 2 calculations, and Scope 2 in the case of the emissions from fertilisers, instead of the approach followed with the BN; (ii) CALM has been around for a much longer period, and the number of users that have provided input data, would have enabled the improvement of the calculations that are being generated. What is striking is the difference in results between the mixed farm and the mixed-renewables farm; making the change seems to have a greater impact according to CALM. At present, the only way of deciding which of the two is correct is by a long term 
and continuous assessment of progress on the farm on GHG emissions, and the impact to the farm's finances that result from the measures implemented to control/reduce them. Finally, CALM uses a deterministic approach, whereas the BNs' underlying framework is probabilistic, therefore the propagation of the uncertainty associated to each of the factors that impact a farm's emissions is not relevant at any stage of the CALM computations.

\subsection{Using Bayesian Networks to estimate GHG emissions from Agriculture (strengths and weaknesses)}

The benefits/weaknesses of developing a Bayesian Network model to estimate the GHGe generated through farming in the UK Agriculture sector, can be summarised in the following manner:

\section{BENEFITS}

- To estimate the GHG emissions generated through Agriculture, it is critically important to assess and manage activities providing the means to sequester GHGe such as soil management practices, and those that release GHGe, such as livestock farming. Calculating the impact of these activities is a difficult problem involving many variables of many types, often with high levels of uncertainty associated with both their measurement and their mechanism of influence. Since the nodes in a BN are modelled by means of probability distributions, risk and uncertainty can be estimated more reliably, making it an appropriate technique for modelling as it has been designed specifically to deal with uncertainty.

- The problem domain requires a hybrid model including continuous and discrete factors. The solution described has demonstrated that a $\mathrm{BN}$ provides the means to build the type of hybrid solution that is necessary.

- Modelling continuous variables is an on-going problem in most BN development environments, given that most of them only support probabilistic inference involving continuous variables through the static discretisation of the variables' domain (Netica, HUGIN EXPERT). The tool used in this study, Agenarisk, incorporates an algorithm, which combines dynamic discretisation with robust propagation on junction tree structures to approximate the distribution of the continuous variables. The approach uses entropy error as the basis for approximation, and by simulating the propagation in junction structures, allows the application of standard operations for evidence multiplication, summation and integration (Neil et al. 2007, 2010). In this manner, it is not necessary to specify in advance an "informed" discretisation of the continuous variables, thereby avoiding the biases experienced with other BN modelling tools (Nash \& Hannah 2011). 
- $\mathrm{BN}$ as a modelling technique includes the means for revising and adjusting the structure of a particular architecture. This is achieved through the application of algorithms for learning Bayesian networks from data (Heckerman et al., 1995). We can update the entire joint distribution of the network as new data becomes available (Krause, 1999), something particularly useful in Agriculture which is continually changing as farmers adapt their working practices to the demands of their surrounding physical, economic and social environment, and as the sources of GHG emissions are better understood.

- The graphical representation of a $\mathrm{BN}$ model facilitates the process of explaining a solution to the problem stakeholders as it not only includes the nodes/factors that are relevant to the problem, it also explicitly describes the channels of inference that are used during the estimation process. The graphical (causal) model representing what can often be a complex joint distribution over many variables help explicate the reasoning in the model in a way that can be quite intuitive to non-modellers.

- It is not necessary to have evidence at hand for all the network inputs. It is possible to propagate partial information through the network, and estimate outputs, the "unknowns" will be reflected in the uncertainty levels associated with the output variables.

- Evidence can be propagated through the network from inputs to outputs and vice-versa. In this manner (as described in Section 3.2, it is possible to feed the network with desired/expected output values, and propagate the information through the network. The resulting model provides an idea of which are the input factors that have greatest influence on the outputs, and also the levels to which these inputs should be reduced and/or increased.

\section{WEAKNESSES}

- The construction of the initial network architecture is a complex problem. It requires inputs from many sources to ensure that all the relevant factors are included in the model. It is not possible to learn from data if there is no factor in the network to encapsulate it.

- The dynamic discretisation inference mechanism that is available in Agenarisk is more powerful than any of the mechanisms available in other tools, nevertheless in order to use it effectively, it is necessary to manage the inputs to a node carefully. For performance purposes, it is not advisable to create a continuous node with more than two inputs going into it, and although it is fairly straightforward to create a network architecture that satisfies this condition, it can make the final structure rather complicated to navigate. 
There are other alternative modelling approaches and it is also useful to assess a solution not only for its goodness-offit to the particularities of the problem domain, it is also important to consider where it stands against other similar modelling approaches. The Monte Carlo simulation (MC) is one such approach, and even though it was not applied to the estimation of GHG emissions, past experience in other application domains, provides the means to discuss its potential against that of the BN. An MC model is also a probabilistic/stochastic model, and captures the process from input variables (farm data, in our case) to outputs (GHGe in our case). However, as discussed in (Smid et al., 2010) MC models have a number of limitations to the scope for modelling the often complex relationships between variables. In contrast, in a BN model, the whole set of variables (the joint probability distribution) is represented as a directed acyclic graph. This is a powerful complexity reduction technique, and also allows (through the use of Bayes' rule and the internal junction tree representation) inference to take place in both a "forward" (from input to output) and a "reverse" direction (from required output, to a candidate set of values that will deliver the required outputs).

This means that as well as handling more accurately situations where there can be interactions between sub-parts of a model, we can also use the model as built to infer changes to the management of a specific farm that will lead to a reduction in GHGe. A general "use less energy" is of course a possible answer. However, the flexibility of the BN approach means that we can condition on any subset of nodes and propagate in order to determine the revised marginal on the remaining nodes. Hence we can fix required outputs and constrain certain inputs that are not possible to change (due to operational constraints on the farm), and see if there are still options to change practice in a cost effective way.

A second advantage of the $\mathrm{BN}$ model is that we can update the entire joint distribution as new data becomes available (Krause, 1999). Of course, it is possible to revise an MC model as new data becomes available, but this process is more dynamic in the $\mathrm{BN}$ domain and we have a more direct interaction between the statistics of the parameters and the simulation model (Barker et al., 2002).

A third advantage of the BN approach is the use of a graphical (causal) model in order to represent what can often be a complex joint distribution over many variables. We are thus able to explicate the reasoning in the model in a way that can be quite intuitive to non-modellers.

A fourth and final benefit is that BNs have been developed in the context of classical decision theory. Thus, we can naturally extend the model to include not just (risk) assessment of the GHGe, but also include in the model an assessment 
of the economic risks and benefits. We believe this is particularly important in the context of decision support for businesses such as farms.

A key weakness of the $\mathrm{BN}$ approach compared with $\mathrm{MC}$, however, is the requirement in most $\mathrm{BN}$ models to discretise continuous variables. Nevertheless, we have been able to handle this effectively through the use of dynamic descretisation as supported by our choice of modelling tool.

A more detailed analysis of the relative strengths and weaknesses of MC and BN approaches can be found in (Smid et al., 2010) (Nash \& Hannah 2011). With the exception of the training of BNs during continued operation, we have demonstrated the value of these aspects of the model in this paper. A key motivation for our work has been to develop a model that is transparent, fully auditable and updatable as more data becomes available. We have been able to build the model using established causal relationships, and build the CPTs using data and equations elicited from papers and guidelines in the public domain. BNs also allow the incorporation of expert knowledge, although this needs to be elicited with care, should there be any areas of the model where data is sparse.

We believe the sources that we have used are currently the best available. Nevertheless, there are some limitations and these will be discussed next.

\subsection{Reliability of the data used to build the model's nodes distributions}

During 2008, an extensive review of the IPCC Guidelines for National GHG Inventories (IPCC, 2006) was carried out, in parallel with a study of the farming data repositories that were available (DEFRA-AUK, 2008; Countryside Survey, 2008; CEH, 2008; UK-NAEI, 2008; CLA, 2010) and the existing mechanisms for counting GHG emissions in the British farming sector (CLA, 2008). This information was used to build the BN to estimate GHG at farm level, and to determine the costs, in terms of SPC, of those emissions. The emissions produced are estimated for each type of farm activity: crop management, livestock management, energy use, and the carbon sequestration potential achieved through the management of the farm's land. The farm's activities and activities' components identified, comply with those covered in the IPCC guidelines tier 1 methodology for GHG estimation. The components covered roughly coincide with those discussed on different publications that deal with the problem of carbon sequestration in land use and the GHG emissions of the agricultural sector (Smith et al. 2008a, 2008b; CALM 2010; Dick et al., 2008). It also complies with the methodology followed by DEFRA (Garrod et al. 1995; Pretty et al. 2005; DEFRA, 2007; DEFRA-Economics Group, 2007), and used to generate the annual report as required by the UK government under the Agriculture Act 1993. Given that the long term goal is to develop a tool that can be of practical use to both, the farming community and policy makers; 
and given that DEFRA is the official governmental body feeding environmental policies and regulations to the agricultural sector (amongst others), this type of compliance facilitates the introduction of the tool into the farming community.

As mentioned earlier, the distributions of the input nodes representing factors of the agricultural sector (such as dairy herd, cropland area) were calculated by dividing the total number recorded for one year (heads of cattle, hectares of land) by the total number of farms registered on that same year. The fact that this information is available for a number of years, allows building a reasonable sample to estimate an initial default distribution for the input node. The downside of this calculation is that there is so much difference across the different farms of the agricultural sector, that the initial estimated distribution is fairly coarse. Nevertheless, in the absence of more accurate information it is a good starting point, and as the farming community begins to use the model, the information each one provides can be used to improve these initial distributions. This is achieved by using the new data to adjust the initial estimates of the network model parameters, revising and adjusting the structure of the model through the application of algorithms for learning Bayesian networks from data (Heckerman et al., 1995).

Improving the estimation of the emission factors, the other type of variable used in the network model, is a more difficult problem given the lack of information available. These estimates can be improved in two different ways. The first is by liaising with research centres that are doing experiments to obtain direct measurements. A second, and shorterterm solution is to use models such as CERES-EGC (Lehuger et al., 2009; Rolland et al. 2008) and feed these outputs to the GHG BN model to improve the accuracy of the current nodes in a similar way as with the agricultural data.

Information on the types and number of sources and sinks of GHG in the UK agricultural sector is a very active research area, specially now when real attempts are being made to try to reduce them. Overall, the sources of GHG are better known than the sinks. As there is not enough data, or a thorough understanding on the sequestering potential of the soil, the distributions used in the carbon sequestering sub-network need further work. For example, the distribution used in the harvested wood products node was estimated using FAO data (FAO 2008). Another aspect that is important to take into consideration is the age of the woodland, because the sequestering rate of a forest changes with time. Even though there is publicly available information on the woodland area in the UK, the data is mostly on National Parks, and it was not possible to identify a publicly available record on the age of the woodland located within the boundaries of the country's farming sector. As in the previous cases, the accuracy of this network component can be improved by revising 
and adjusting the network estimates, something that will occur with time as more information is gathered from users of the model, i.e. the farmers, as they constitute the best data sources for improving its future accuracy and reliability.

A final question that impinges on the reliability and accuracy of the estimation of a farm's annual GHG inventory refers to the specification of its production process boundaries. According to the standards (PAS 2050:2008; GHGProtocol, WRI 2010); a thorough GHG estimation process should cover the production line from cradle to grave, and cater for what happens to the inputs/outputs used/generated on the farm. Scope $1 \mathrm{GHG}$ calculations are limited to the strict geographical boundaries of the farm; Scope 2 and Scope 3 calculations encompass what happens to inputs and outputs before and after entering or leaving the farm, in compliance with the GHG-Protocol (WRI 2010). These "boundaries" can make a big difference to the complexity of the calculations, and also to the final value of the farm's "carbon footprint". Therefore, it is important to be clear about what they are. As there is no official consensus on what they should be, the BN model developed in this study estimates the tier 1, scope $1 \mathrm{GHG}$ emissions, i.e. the annual carbon footprint of a farm. The indirect emissions produced via the energy consumed could be viewed as scope 2 , but as this is the only type of emission, of the ones currently considered, outside scope 1, no real distinction is made between these two levels when reporting the farm's total emissions.

\section{Conclusions and Research Challenges}

A number of tools have already been designed for the purpose of estimating the emissions generated by various types of human activities, in particular those emissions that the farming sector is responsible for (CLA, 2010; GHG-PI, 2010). A pervading theme in all the solutions reviewed is the need to handle the uncertainty associated to this type of calculation. The tool described here has the advantage of being based on a probabilistic framework; therefore it is not necessary to incorporate additional mechanisms to manage this problem. It constitutes another example of an objectoriented bayesian network, as described in (Neil et al. 2000). The model described herein is built for an environmental application, reminiscent of the model developed by Molina et al. (2010) for a water management application. The similarity stems in the complexity of the realities that are being modelled and how, in both cases, object oriented networks was the preferred tool of choice to handle it. 
In addition to the above, the contribution of this study to the body of research in Environmental Engineering can be summarised as follows:

1. The development of a BN to estimate the annual GHG emissions of a British farm.

2. By extending the model to estimate the potential financial impact to the farm caused by the GHG emissions that result from their working practices, the farmers should get a better perspective on the environmental impact of their business and be persuaded on the subject of deploying more environmentally friendly working practices. This is achieved by linking the farm's annual income to the SPC resulting from the farm's operations.

3. The development of a tool that can be used without the need to perform complicated pre-processing of the output of the model before the information can be seen in a format that is useful for reviewing a farm's production plan.

4. A tool for researchers that can be used to study further the financial implications of the environmental policies that are constantly being issued. This provides a means to define more effective regulations that are realistic and easier for the community to adopt.

Feedback on the tool from the farming community has so far been very positive. However, there are some who are of the opinion that there is not much they can change from their current practices to mitigate the emissions on their farm. This makes it even more important to map these emissions into a monetary value, and set up appropriate incentivisation mechanisms, as this will provide the farmers with a better tool to decide on how to manage and reduce their emissions.

More evidence-based research is needed. We strongly advocate use of BN based tools as they explicitly handle the uncertainties in any assessment or prediction. The limitations described in (Nash \& Hannah, 2011), regarding the generation of "invalid results" if the nodes' states are not carefully selected, is partly resolved with the choice of BN tool, given the "dynamic discretisation" feature available in AgenaRisk. Solutions for analysing evidence are already deployed, with CALM being a well-known example. However, even though it is supplying the farming community with information on their environmental impact, it does not provide the farmers with more tangible links on the implications to their business. Consequently, there is no guarantee that they will take a proactive approach in reducing it. Neither is it possible to explore the effect of reducing the GHG emissions to a pre-defined level, and back-propagating this information through the model, as was shown in the case study described. This last feature can be extremely useful to all the stakeholders involved in the design and deployment of a farm's production plan. 
The research results described clearly show potential for using $\mathrm{BN}$ models in this type of application. In order to achieve more accurate results it is necessary to:

- develop further the network built to estimate the carbon sequestration potential of the farm;

- improve the probability distributions used by liaising directly with farmers working in the agricultural sector, and other research groups actively involved in gathering evidence on the environmental impact caused by this economic sector;

- the cost/benefit analysis currently carried out to integrate the network's SPC estimates to the rest of the farm's financial data can be improved by creating another network component, one that estimates the farm's expected returns and combines the results with the environmental costs computed by the other network components. This is current on-going research, and the results of this extension to the model will be described in future publications.

All these tasks are part of the plan currently being defined to continue with this research.

In conclusion, although we have an on-going programme of work to continue to refine the tool, we believe that the tool as it stands makes a significant contribution to the availability of open and accountable assessment tools for GHG emissions in the agricultural sector. The model is both interpretable by non-expert modellers and easily revisable as more data and ground truth becomes available. It is designed from the start to fit naturally into both the processes of management of a farm as a business and the processes of policy formulation, through the inclusion of economic impact within the model. As a result, we believe that $\mathrm{BN}$ modelling has an extremely important role to play in managing Green House Gas emissions in the agricultural sector. 


\section{Appendix A. Volume 4: Agriculture, Forestry and Other Land Use. List of tier 1 equations used in network model}

\begin{tabular}{|c|c|}
\hline BN network & IPCC equations \\
\hline $\begin{array}{l}\text { Fertilisers(Nitrogen \& } \\
\text { Urea) }\end{array}$ & $\begin{array}{l}\text { - Direct N2O Emissions from Managed Soils (equation 11.1) } \\
\text { - Urea Fertilization: Annual CO2 emissions from Urea Fertilization (equation 11.13) } \\
\text { - Liming: Annual CO2-C emissions from Liming (equation 11.12) }\end{array}$ \\
\hline $\begin{array}{l}\text { Farm CROPS\&LUC } \\
\text { emissions }\end{array}$ & $\begin{array}{l}\text { - Land Converted to Grassland (equations } 2.15,2.16,2.23,2.25 \text { ) } \\
\text { - Land Converted to Cropland (equations } 2.15,2.16,2.23,2.25 \text { ) } \\
\text { - CL remaining CL (equations } 2.7,2.25 \text { ) } \\
\text { - GL remaining GL (equations } 2.25 \text { ) } \\
\text { - FL burning (equation 2.6) }\end{array}$ \\
\hline $\begin{array}{l}\text { Farm Carbon } \\
\text { sequestration }\end{array}$ & $\begin{array}{l}\text { - Land Converted to Forest Land: Annual increase in carbon stocks in biomass } \\
\text { (equations } 2.72 .92 .122 .13 \text { ) } \\
\text { • FL remaining FL (equations } 2.92 .102 .122 .13 \text { ) } \\
\text { • HWP } \\
\text { • (Product Consumption = Production + Imports - Exports) } \\
\text { • used FAO data to estimate product consumption. } \\
\text { • Default factors are used to convert solid-wood and paper from volume } \\
\text { units to carbon units. } \\
\text { • used Regional rates of change in industrial round-wood production. } \\
\text { •used default factors for Half-lives for products in use }\end{array}$ \\
\hline Farm livestock & $\begin{array}{l}\text { - Methane Emissions from Enteric Fermentation and Manure Management (equations } \\
\text { 10.19, 10.20,10.22) } \\
\text { •Direct N2O Emissions from Manure Management Systems (equation 10.25) } \\
\text {-Indirect N2O Emissions from Manure Management (equation 10.25, 10.26, 10.27) }\end{array}$ \\
\hline
\end{tabular}




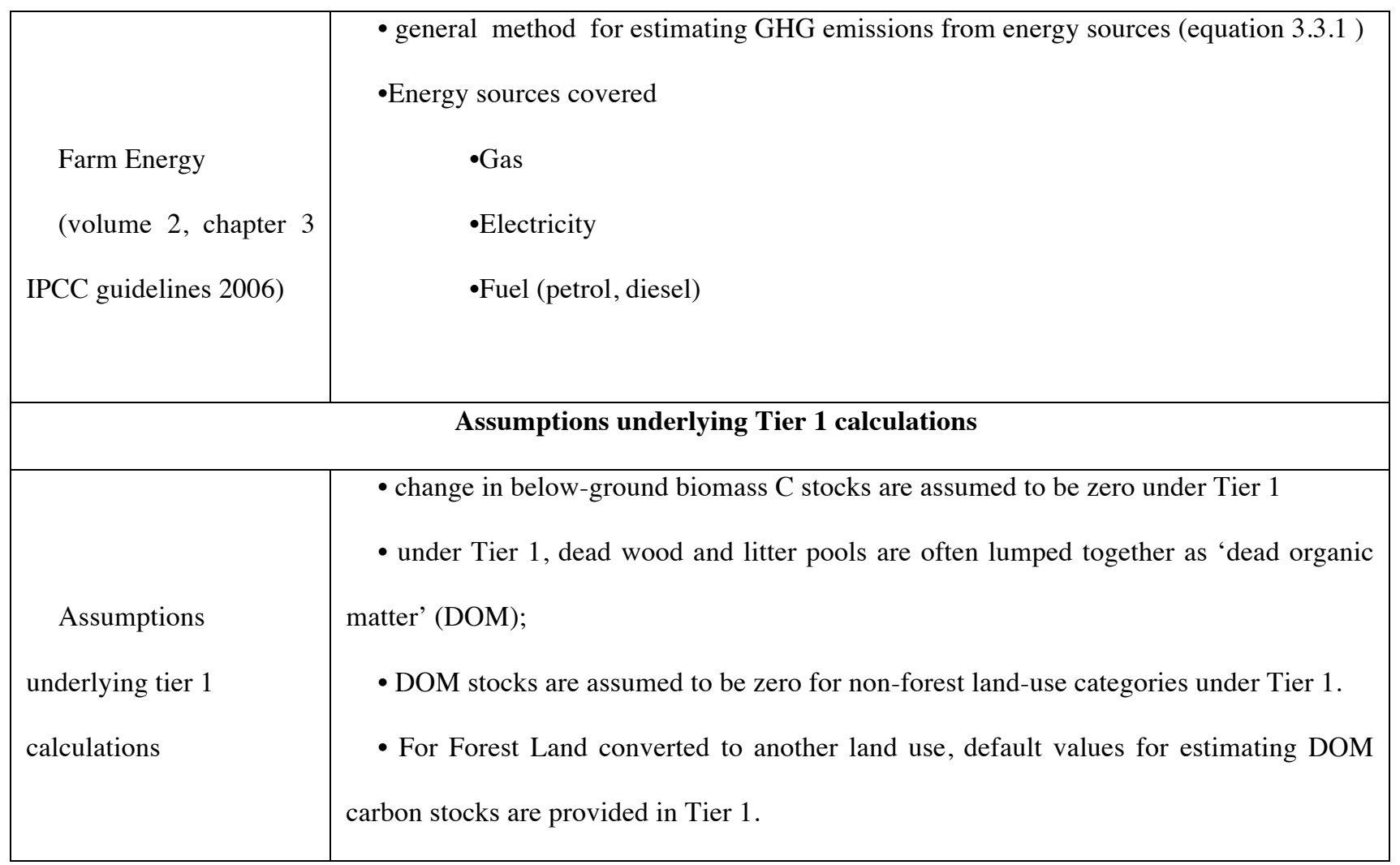

Table A.1 IPCC guidelines: equations and assumptions used in each sub-network of the GHG emissions BN 


\section{Appendix B BN model. Probability distributions information of the network's input/output nodes}

The information presented in Tables B.1, and B.2 describe the prior probability distributions of the input and output nodes that were defined in the BN for GHG estimation model described in this publication. The rows shaded in grey are labelled with the name of one of the sub-networks that are part of the model. There are 5 sub-networks (Figure 1) therefore there are 5 rows shaded in gray. Each of the other rows corresponds to one node in the model. The table has 9 columns. The first one includes the descriptive name of the node. The second column describes the units of measurement for the relevant node. The third column includes the node's unique identifier in the model. Columns 4-9 provide the information that describes the node's probability distribution; i.e. the mean, the median, the standard deviation, the variance, the lower percentile (25\%), and the upper percentile $(75 \%)$. The node names listed under each gray row correspond to the names of the input/output nodes for that particular sub-network. 


\begin{tabular}{|c|c|c|c|c|c|c|c|c|}
\hline Node name & Units & Node_id & Mean & Median & Variance & Standard Deviation & \begin{tabular}{|l} 
Lower \\
Percentile
\end{tabular} & Upper Percentile \\
\hline \multicolumn{9}{|l|}{ Livestock sub-network } \\
\hline Pigs & heads & pigs & 439.63 & 439.80 & 135204.34 & 367.70 & 192.39 & 687.38 \\
\hline Dairy herd & heads & d_h & 80.44 & 79.80 & 1078.43 & 32.84 & 58.82 & 100.47 \\
\hline Cattle & heads & o_cattle & 56.96 & 56.63 & 28.87 & 5.37 & 53.00 & 61.00 \\
\hline Sheep & heads & sheep & 274.36 & 273.96 & 5111.36 & 71.49 & 230.76 & 317.36 \\
\hline Goats & heads & goats & 8.30 & 8.00 & 4.58 & 2.14 & 7.00 & 10.00 \\
\hline Horses & heads & horses & 9.93 & 10.00 & 30.10 & 5.49 & 6.00 & 14.00 \\
\hline Poultry & heads & poultry & 336.39 & 336.44 & 4008.09 & 63.31 & 293.75 & 379.00 \\
\hline Other birds & heads & Other B & 29.47 & 27.45 & 331.99 & 18.22 & 15.20 & 41.28 \\
\hline \multicolumn{9}{|c|}{ Farm Use of Fertilisers, Crops\&Land Use Change Emissions sub-network } \\
\hline Farmland & hectares & FarmL & 159.26 & 82.22 & 47436.29 & 217.80 & 25.15 & 201.60 \\
\hline Cropland area & hectares & CL_A & 90.88 & 62.64 & 8538.99 & 92.41 & 26.32 & 124.57 \\
\hline Grassland area & hectares & GL_A & 60.73 & 41.43 & 3886.49 & 62.34 & 17.36 & 83.25 \\
\hline Forestland area & hectares & FL_A & 7.33 & 7.32 & 5.93 & 2.44 & 5.68 & 8.97 \\
\hline $\begin{array}{l}\text { Land converted to } \\
\text { Grassland } \\
\end{array}$ & hectares & LC_GL & 1.64 & 1.58 & 0.54 & 0.74 & 1.09 & 2.12 \\
\hline $\begin{array}{l}\text { Land converted to } \\
\text { Cropland }\end{array}$ & hectares & LC_to_CL_A & 0.56 & 0.48 & 0.18 & 0.42 & 0.23 & 0.81 \\
\hline Emission factor CT & tonnes C*ha-1 & EF_CT & 5.00 & 5.00 & 5.86 & 2.42 & 3.01 & 6.99 \\
\hline Carbon stock & tonnes $\mathrm{C}$ & CS_LCtCL & -183.49 & -183.49 & 72.18 & 8.50 & -189.14 & -177.83 \\
\hline Dolomite & tonnes & dolomite & 1.54 & 1.43 & 0.93 & 0.96 & 0.78 & 2.16 \\
\hline Limestone & tonnes & limestone & 1.71 & 1.56 & 1.23 & 1.11 & 0.83 & 2.42 \\
\hline Nitrogen_grass & tonnes & N_GL & 1.87 & 1.58 & 2.00 & 1.41 & 0.74 & 2.69 \\
\hline Nitrogen_crops & tonnes & N_CL & 4.31 & 3.73 & 9.79 & 3.13 & 1.81 & 6.19 \\
\hline Urea & tonnes & tUrea & 6.01 & 6.00 & 4.37 & 2.09 & 4.58 & 7.42 \\
\hline \multicolumn{9}{|c|}{ Carbon Sequestration sub-network } \\
\hline Carbon_sequestration & tonnes $\mathrm{CO} 2 \mathrm{e}$ & Carbon_s & -48.50384882 & -48.450821 & 313.0818327 & 17.69411859 & -59.41337595 & -37.37021518 \\
\hline $\begin{array}{l}\text { Forestland remaining } \\
\text { Forestland }\end{array}$ & hectares & FLrFL & -47.92 & -47.89 & 270.93 & 16.46 & -58.70 & -36.96 \\
\hline \begin{tabular}{|l|} 
Harvested Wood \\
Products tonnes $\mathrm{CO}_{2} \mathrm{e}$ \\
\end{tabular} & tonnes $\mathrm{CO} 2 \mathrm{e}$ & HWPe & -0.47 & -0.47 & 1.63 & 1.28 & -1.33 & 0.40 \\
\hline Forestland area & hectares & FL_A & 7.33 & 7.32 & 5.93 & 2.44 & 5.68 & 8.97 \\
\hline Carbon gain $\mathrm{FL}$ & tonnes C*ha-1 & $\mathrm{CgFL}$ & 13.25 & 13.21 & 20.19 & 4.49 & 10.23 & 16.20 \\
\hline Carbon loss FL & tonnes C*ha-1 & $\mathrm{ClFL}$ & 0.19 & 0.19 & 0.00 & 0.06 & 0.15 & 0.23 \\
\hline $\begin{array}{l}\text { Land converted to } \\
\text { Forestland } \\
\end{array}$ & hectares & LC_FL & 0.00 & 0.00 & 0.00 & 0.01 & -0.01 & 0.01 \\
\hline $\begin{array}{l}\text { Forestland contribution } \\
\text { tonnes } \mathrm{CO}_{2} \mathrm{e}\end{array}$ & tonnes $\mathrm{CO} 2 \mathrm{e}$ & FLC & -47.94420462 & -47.886904 & 294.4802686 & 17.1604274 & -58.70342387 & -36.96120824 \\
\hline
\end{tabular}

Table B.1 BN model. Probability distributions for input/output nodes. Livestock, Carbon sequestration, Farm use of fertilisers and LU sub-networks 


\begin{tabular}{|c|c|c|c|c|c|c|c|c|}
\hline Node name & Units & Node_id & Mean & Median & Variance & Standard Deviation & Lower Percentile & Upper Percentile \\
\hline \multicolumn{9}{|c|}{ Farm Energy emissions sub-network } \\
\hline Emissions Fuel products & Kgs $\mathrm{CO} 2 \mathrm{e}$ & E_FP & 34435.69 & 33990.11 & 166362230.93 & 12898.15 & 25473.20 & 43079.66 \\
\hline Burning oil & KWhrs & $\mathrm{BO}$ & 2611.47 & 2542.40 & 1796239.40 & 1340.24 & 1613.44 & 3512.03 \\
\hline $\begin{array}{l}\text { Emission Factor } \\
\text { electricity }\end{array}$ & Kgs CO2 & $E F \_E$ & 0.58 & 0.58 & 0.01 & 0.08 & 0.53 & 0.64 \\
\hline Emissions Electricity & Kgs CO2e & $\mathrm{EE}$ & 24957.94 & 23656.30 & 201423237.08 & 14192.37 & 14232.79 & 33996.77 \\
\hline Emissions Gas Oil Diesel & Kgs CO2e & E_GOD & 34434.90 & 34209.83 & 159060454.57 & 12611.92 & 25537.00 & 42942.89 \\
\hline Emissions Burning Fuel & Kgs CO2e & $\mathrm{E} \_\mathrm{BO}$ & 59139.32 & 56349.43 & 974751230.34 & 31221.01 & 35104.57 & 79557.99 \\
\hline Farm Energy Emissions & Tonnes $\mathrm{CO}_{2} \mathrm{e}$ & eFE & 89.50 & 88.63 & 533.61 & 23.10 & 73.56 & 104.36 \\
\hline Gas Oil & KWhrs & GO_D & 18992.51 & 17973.37 & 124251616.54 & 11146.82 & 10358.62 & 26340.55 \\
\hline tractors consumption & litres & tractors_c & 8387.60 & 8256.60 & 15562000.00 & 3944.80 & 5541.80 & 11042.00 \\
\hline tractors $\mathrm{EF}$ & Kgs $\mathrm{CO} 2$ per unit & tractors_EF & 2.64 & 2.64 & 0.000001 & 0.000991 & 2.64 & 2.64 \\
\hline Emissions Machinery & $\mathrm{Kgs} \mathrm{CO} 2 \mathrm{e}$ & Em_M & 22149.00 & 21795.00 & 110100000.00 & 10493.00 & 14546.00 & 29141.00 \\
\hline RE emissions & Tonnes $\mathrm{CO} 2 \mathrm{e}$ & eREe_CHP & 7.94 & 6.76 & 32.21 & 5.68 & 3.59 & 11.07 \\
\hline \multicolumn{9}{|c|}{ Farm total GHGe sub-network } \\
\hline \begin{tabular}{|l|} 
Livestock Methane \\
emissions_tonnes $\mathrm{CO} 2 \mathrm{e}$
\end{tabular} & tonnes $\mathrm{CO} 2 \mathrm{e}$ & LS_CH4 & 617.97 & 636.43 & 49181.61 & 221.77 & 464.96 & 792.83 \\
\hline \begin{tabular}{|l|} 
Crops $\mathrm{CH} 4$ \\
emissions_tonnes $\mathrm{CO}_{2} \mathrm{e}$ \\
\end{tabular} & tonnes $\mathrm{CO} 2 \mathrm{e}$ & Crops_CH4 & 2.54 & 2.44 & 2.02 & 1.42 & 1.46 & 3.49 \\
\hline $\begin{array}{l}\mathrm{N} 2 \mathrm{O} \text { CO2e managed } \\
\text { soils_tonnes } \mathrm{CO}^{\mathrm{e}} \mathrm{e}\end{array}$ & tonnes $\mathrm{CO} 2 \mathrm{e}$ & MS_N2O & 0.22 & 0.22 & 0.01 & 0.09 & 0.15 & 0.28 \\
\hline \begin{tabular}{|l|} 
Livestock $\mathrm{NxO} \mathrm{CO}_{2} \mathrm{e}$ \\
emissions_tonnes $\mathrm{CO} 2 \mathrm{e}$
\end{tabular} & tonnes $\mathrm{CO} 2 \mathrm{e}$ & LS_N2O & 0.18 & 0.18 & 0.01 & 0.10 & 0.11 & 0.25 \\
\hline Crops $\mathrm{CO}^{2} \mathrm{e}$ tonnes $\mathrm{CO} 2 \mathrm{e}$ & tonnes $\mathrm{CO} 2 \mathrm{e}$ & Crops_CO2e & -12.57 & -12.57 & 252.35 & 15.89 & -23.20 & -1.90 \\
\hline \begin{tabular}{|l|} 
Carbon sequestration \\
CO2e tonnes
\end{tabular} & tonnes $\mathrm{CO} 2 \mathrm{e}$ & Seq_MS & -37.44 & -37.47 & 275.09 & 16.59 & -48.60 & -26.30 \\
\hline \begin{tabular}{|l|} 
Energy Tonnes $\mathrm{CO} 2 \mathrm{e}$ \\
emissions
\end{tabular} & tonnes $\mathrm{CO} 2 \mathrm{e}$ & Ee & 31.19 & 31.18 & 71.94 & 8.48 & 25.45 & 36.92 \\
\hline Total Farm GHGe & tonnes $\mathrm{CO} 2 \mathrm{e}$ & T_F_GHGe & 601.61 & 618.89 & 50377.80 & 224.45 & 447.18 & 778.01 \\
\hline Shadow Price of Carbon & GBP & SPC & 196.92 & 179.29 & 17936.56 & 133.93 & 90.75 & 283.01 \\
\hline $\begin{array}{l}\text { Farm Environmental } \\
\text { Costs }\end{array}$ & GBP & F_SPC & 798.72 & 809.71 & 70155.87 & 264.87 & 617.96 & 986.31 \\
\hline
\end{tabular}

Table B.2 model. Probability distributions for input/output nodes. Farm Energy and Farm Total GHGe sub-

\section{networks}




\begin{tabular}{|c|c|c|c|c|}
\hline \multicolumn{5}{|l|}{ Farm total GHGe sub-network } \\
\hline Node Name & Node Id & Node Parents & Node Equation & Units \\
\hline Livestock Methane emissions_tonnes $\mathrm{CO}_{2} \mathrm{e}$ & LS_CH4 & Farm livestock emissions sub-network & $\begin{array}{l}\text { sub-network output is fed to the Farm } \\
\text { Total GHGe sub-network }\end{array}$ & tonnes $\mathrm{CO} 2 \mathrm{e}$ \\
\hline Crops $\mathrm{CH} 4$ emissions_tonnes $\mathrm{CO} 2 \mathrm{e}$ & Crops_CH4 & Farm CROPS\&LUC emissions sub-network & $\begin{array}{l}\text { sub-network output is fed to the Farm } \\
\text { Total GHGe sub-network }\end{array}$ & tonnes $\mathrm{CO} 2 \mathrm{e}$ \\
\hline $\mathrm{N} 2 \mathrm{O} \mathrm{CO} 2 \mathrm{e}$ managed soils_tonnes $\mathrm{CO} 2 \mathrm{e}$ & MS_N2O & Fertilisers (Nitrogen\&Urea) sub-network & $\begin{array}{l}\text { sub-network output is fed to the Farm } \\
\text { Total GHGe sub-network }\end{array}$ & tonnes $\mathrm{CO} 2 \mathrm{e}$ \\
\hline Livestock $\mathrm{NxO} \mathrm{CO}_{2} \mathrm{e}$ emissions_tonnes $\mathrm{CO} 2 \mathrm{e}$ & LS_N2O & Farm livestock emissions sub-network & $\begin{array}{l}\text { sub-network output is fed to the Farm } \\
\text { Total GHGe sub-network }\end{array}$ & tonnes $\mathrm{CO} 2 \mathrm{e}$ \\
\hline Crops $\mathrm{CO}_{2} \mathrm{e}$ tonnes $\mathrm{CO} 2 \mathrm{e}$ & Crops_CO2e & Farm CROPS\&LUC emissions sub-network & $\begin{array}{l}\text { sub-network output is fed to the Farm } \\
\text { Total GHGe sub-network }\end{array}$ & tonnes $\mathrm{CO} 2 \mathrm{e}$ \\
\hline Carbon sequestration $\mathrm{CO} 2 \mathrm{e}$ tonnes & Seq_MS & Farm Carbon Sequestration sub-network & $\begin{array}{l}\text { sub-network output is fed to the Farm } \\
\text { Total GHGe sub-network }\end{array}$ & tonnes $\mathrm{CO} 2 \mathrm{e}$ \\
\hline Energy Tonnes CO2e emissions & Ee & Farm Energy emissions sub-network & $\begin{array}{l}\text { sub-network output is fed to the Farm } \\
\text { Total GHGe sub-network }\end{array}$ & tonnes $\mathrm{CO} 2 \mathrm{e}$ \\
\hline Total N2O_CO2e & T_N2O & MS_N2O LS_N2O & MS_N2O+LS_N2O & tonnes $\mathrm{CO} 2 \mathrm{e}$ \\
\hline Total CH4_CO2e & T_CH4 & & LS_CH4+Crops_CH4 & tonnes $\mathrm{CO} 2 \mathrm{e}$ \\
\hline Total Soil Management $\mathrm{CO} 2 \mathrm{e}$ & T_SM_e & $\begin{array}{l}\text { Seq_MS } \\
\text { Crops_CO2e }\end{array}$ & Seq_MS+Crops_CO2e & tonnes $\mathrm{CO} 2 \mathrm{e}$ \\
\hline Total CH4_N2O & T_CH4_N2O & T_N2O T_CH4 & T_N2O+T_CH4 & tonnes $\mathrm{CO} 2 \mathrm{e}$ \\
\hline Total Sequestration and SM & T_S_SM & T_SM_e Ee & T_SM_e+Ee & tonnes $\mathrm{CO} 2 \mathrm{e}$ \\
\hline Total Farm GHGe & T_F_GHGe & T_CH4_N2O T_S_SM & T_CH4_N2O+T_S_SM & tonnes $\mathrm{CO} 2 \mathrm{e}$ \\
\hline Shadow Price of Carbon & SPC & $\mathrm{N}(131.59,31360.7)$ & $\begin{array}{l}\text { input node with normal distribution - } \\
\text { it is set to a constant value } f 25 \text {, the }\end{array}$ & pounds stirling (f) \\
\hline Farm Environmental Costs & F_SPC & SPCT_F_GHGe & SPC*T_F_GHGe & pounds stirling $(f)$ \\
\hline
\end{tabular}

Table B.3 Node equations. Farm Total GHGe sub-network

\section{References}

Aalders I., 2008. Modelling Land-Use Decision Behaviour with Bayesian Belief Networks. Ecology and Society 13(1):16, 231-242.

AgenaRisk, 2010. Bayesian Network and Simulation Software for Risk Analysis and Decision Support. http://www.agenarisk.com/ .

Barker, G.C., Talbot, N.L.C, Peck, M.W. 2002. Risk assessment for Clostridium botulinum: a network approach. International Biodeterioration \& Biodegradation 50, 45-47.

Bellarby, J., Foereid, B., Hastings, A., Smith, P., 2008. Cool Farming: Climate Impacts of Agriculture and Mitigation

Potential. Greenpeace International, Amsterdam, The Netherlands. 43pp. 
BS-EN-ISO 14044:2006, 2006. Environmental management -Life cycle assessment- Requirements and guidelines.

BS ISO 14064-1:2006, 2006. Greenhouse gases -- Part 1: Specification with guidance at the organization level for quantification and reporting of greenhouse gas emissions and removals.

BS ISO 14064-2:2006, 2006. Greenhouse gases -- Part 2: Specification with guidance at the project level for quantification, monitoring and reporting of greenhouse gas emission reductions or removal enhancements.

BS ISO 14064-3:2006, 2006. Greenhouse gases -- Part 3: Specification with guidance for the validation and verification of greenhouse gas assertions.

Cain J.D., Jinapala K., Makin I.W., Somaratna P.G., Ariyaratna B.R., Perera L.R., 2003. Participatory decision support for agricultural management. A case study from Sri Lanka. Elsevier, Agricultural Systems, 76, 457-482.

Clark J., 2005. Why environmental scientists are becoming Bayesians. Ecology Letters 8, 2-14.

Centre for Ecology and Hydrology (CEH), 2008. CEH Data Holdings, http://www.ceh.ac.uk/data/index.html

Country Land and Business Association (CLA), 2010. http://www.cla.org.uk/ .

Country Land and Business Association (CLA), 2010. CALM: Carbon Accounting for Land Managers, http://www.calm.cla.org.uk/ .

Countryside Survey, 2008. Countryside Survey http://www.countrysidesurvey.org.uk/

Das B., 1999. Generating Conditional Probabilities for Bayesian Networks: Easing the Knowledge Acquisition Problem. Information Technology Division, Electronics and Surveillance Research Laboratory. DSTO Report, DSTO-TR-0918.

Department of Energy and Climate Change (DECC) 2011.

http://www.decc.gov.uk/en/content/cms/consultations/fit_review/fit_review.aspx

Department for Environment, Food and Rural Affairs (DEFRA) 2011. http://www.defra.gov.uk/corporate/index.htm

DEFRA 2007. DEFRA, Economics and Statistics. https://statistics.defra.gov.uk/esg/

DEFRA-Economics Group: Price R., Thornton S., Nelson S., 2007. The Social Cost of Carbon and the Shadow Price of Carbon: What they are, and How to Use them In Economic Appraisal in the UK, Department of Environment, Food, and Rural Affairs report, http://www.decc.gov.uk/en/content/cms/what_we_do/lc_uk/valuation/shadow_price/shadow_price.aspx (accessed October 2011)

DEFRA-AUK 2008. Agriculture in the United Kingdom (AUK). http://www.defra.gov.uk/evidence/statistics/foodfarm/general/auk/latest/documents/AUK-2009.pdf 
DEFRA, DECC 2009. 2009 Guidelines to DEFRA/DECC's GHG Conversion Factors for Company Reporting. http://www.defra.gov.uk/environment/business/reporting/conversion-factors.htm

DEFRA-BSFP 2009. The British Survey of Fertiliser Practice: Fertiliser use on farm crops for crop year 2009. http://www.defra.gov.uk/evidence/statistics/foodfarm/enviro/fertiliserpractice/index.htm

Dick J., Smith P., Smith R., Lilly A., Moxey A., Booth J., Campbell C., Coulter D., 2008. Calculating farm scale greenhouse gas emissions. Internal Report, CPLAN. www.cplan.org.uk/Calculating GHG Report.pdf

Dlamani W.M., 2010. A Bayesian belief network analysis of factors influencing wildfire occurrence in Swaziland. Elsevier, Environmental Modelling \& Software 25, 199-208.

Ekins P., 2003. Identifying critical natural capital Conclusions about critical natural capital. Ecological Economics 44, 277-292.

FAO, 2008. Food and Agriculture Organization of the UN (FAO). http://faostat.fao.org/

Fenton N., Krause P., Neil M., 1999. A Probabilistic Model for Software Defect Prediction. IEEE Transactions in Software Engineering.

Forster, P., V. Ramaswamy, P. Artaxo, T. Berntsen, R. Betts, D.W. Fahey, J. Haywood, J. Lean, D.C. Lowe, G. Myhre, J. Nganga, R. Prinn, G. Raga, M. Schulz and R. Van Dorland, 2007. Changes in Atmospheric Constituents and in Radiative Forcing. In: Climate Change 2007: The Physical Science Basis. Contribution of Working Group I to the Fourth Assessment Report of the Intergovernmental Panel on Climate Change [Solomon, S., D. Qin, M. Manning, Z. Chen, M. Marquis, K.B. Averyt, M.Tignor and H.L. Miller (eds.)]. Cambridge University, Press, Cambridge, United Kingdom and New York, NY, USA.

Garrod G., Willis, K. 1995. Valuing the Benefits of the South Downs Environmentally Sensitive Area, Journal of Agricultural Economics 46,2, 160- 173.

GES, Glossary of Environment Statistics, United Nations, 1997, Glossary of Environment Statistics, Studies in Methods, Series F, No. 67, UN, New York.

GHG-Protocol, GHG Protocol Initiative (GHG-PI), 2010. Tools provided by the GHG Protocol, http://www.ghgprotocol.org/calculation-tools .

Gras J., McGaw D., 2004. End-to-End Defect Prediction, In: Proc. 15th IEEE International Symposium on Software Reliability Engineering ( ISSRE'2004). 
Heckerman D., Geiger D. and Chickering D.M., 1995. Learning Bayesian Networks: The Combination of Knowledge and Statistical Data. Machine Learning, 20, 197-243.

HUGIN EXPERT, 2010. A/S, Hugin tool. http://www.hugin.com/ .

Hutchinson JJ, Campbell CA, Desjardins RJ, 2007. Some perspectives on carbon sequestration in agriculture. Elsevier, Agricultural and Forest Meteorology 142, 288-302.

IPCC 2006. 2006 IPCC Guidelines for National Greenhouse Gas Inventories, Prepared by the National Greenhouse Gas Inventories Programme, Eggleston H.S., Buendia L., Miwa K., Ngara T. and Tanabe K. (eds)., IGES, Japan.

IPCC 1995. IPCC Second Assessment Climate Change 1995. A report of the Intergovernmental Panel on Climate Change.

Krause P., 1999. Learning Probabilistic Networks, Knowledge Engineering Review 13, 321-351.

Lehuger S., Gabrielle B., van Oijen M., Makowski D., Germon J.-C., Morvan T., Henault C., 2009. Bayesian calibration of the nitrous oxide emission module of an agro-ecosystem model. Agriculture Ecosystems \& Environment 133, 208222.

Ma L, Arentze T, Borgers A, Timmermans H, 2007. Modelling land-use decisions under conditions of uncertainty. Elsevier Computers, Environment and Urban Systems 31, 461-476.

McCarl B.A., Sands R.D., 2007. Competitiveness of terrestrial greenhouse gas offsets: are they a bridge to the future? Climatic Change, 80, 109-126.

Molina J.L., Bromley J., García-Aróstegui J.L., Sullivan C., Benavente J., 2010. Integrated water resources management of overexploited hydrogeological systems using Object-Oriented Bayesian Networks. Environmental Modelling \& Software 25, 383-397.

Nash D, Hannah M, 2011. Using Monte-Carlo simulations and Bayesian Networks to quantify and demonstrate the impact of fertiliser best management practices. Elsevier, Environmental Modelling \& Software 26, 1079-1088.

Natural England (NE), 2010. http://www.naturalengland.org.uk/ .

Neftel A, Fischer C, Flechard Ch, 2006. Measurements of greenhouse gas fluxes from agriculture. Elsevier, International Congress Series 1293, 3-12.

Neil, M., Marquez, D., 2010. Availability modelling of repairable systems using Bayesian networks. Engineering Applications of Artificial Intelligence. doi:10.1016/j.engappai.2010.06.003 . 
Neil M., Tailor M., Fenton N., 2007. Inference in hybrid Bayesian Networks using dynamic discretization. Statistics and Computing, 17(3), 219-233.

Neil M., Fenton N., Nielsen L., 2000. Building Large-Scale Bayesian Networks. Cambridge University Press, Knowledge Engineering Review, 15, 3, 257-284.

Newton A, 2010. Use of a Bayesian network for Red Listing under uncertainty. Elsevier, Environmental Modelling \& Software $25,15-23$.

Norsys Software Corp, 2010. Netica tool. www.norsys.com .

PAS 2050:2008, 2008. Specification for the assessment of the life cycle greenhouse gas emissions of goods and services. http://shop.bsigroup.com/en/Browse-by-Sector/Energy--Utilities/PAS-2050/ .

Pérez-Miñana E., 2009. Bayesian Belief Networks for the management of GHG emissions in the UK agricultural sector. MSc Advanced Energy and Environmental Studies Thesis, University of East London.

Pretty J.N., Ball A.S., Lang T., Morison J.I.L., 2005. Farm costs and food miles: An assessment of the full cost of the UK weekly food basket. Food Policy,30,1, 1-19.

Rolland M.N., Gabrielle B., Laville P., Serca D., Cortinovis J., Larmanou E., Lehuger S., Cellier P., 2008. Modelling of nitric oxide emissions from temperate agricultural soils. Nutrient Cycling in Agroecosystems, 80, 75-93.

Smid J.H., Verloo D., Baker G.C., Havelaar A.H. 2010. Strengths and weaknesses of Monte Carlo simulation models and Bayesian belief networks in microbial risk assessment. International Journal of Food Microbiology 139, S57-S63.

Smith P., 2007. Land use change and soil organic carbon dynamics. Nutrient Cycling in Agroecosystems, 81, 2, 169-178.

Smith P., Fang C., Dawson J.J.C., Moncreiff J.B. 2008a. Impact of global warming on soil organic carbon. Advances in Agronomy, 97, 1-43.

Smith P., Nabuurs G-J., Janssens I., Reis S., Marland G, Soussana J.-F., Christensen T.R., Heath L., Apps, M., Alexeyev V, Fang J.Y., Gattuso J.-P., Guerschman J.P., Huang Y., Jobbagy E., Murdiyarso D., Ni J., Nobre A., Peng C.H., Walcroft A., Wang S.Q., Pan Y., Zhou G.S. 2008b. Sectoral approaches to improve regional carbon budgets. Climatic Change, 88, 3-4, 209-249.

Sneddon S., Brophy N., Li Y., MacCarthy J., Martinez C., Murrells T., Passant N., J Thomas, Thistlethwaite G., Tsagatakis I., H Walker, Thomson A., Cardenas L., 2010. Greenhouse Gas Inventories for England, Scotland, Wales and Northern Ireland: 1990 - 2008. Report AEAT/ENV/R/3067 Issue 1.

http://www.airquality.co.uk/reports/reports.php?action=category\&section_id=7 
UKs NAEI, 2008. UKs National Atmospheric Emissions Inventory (NAEI). http://www.naei.org.uk/

Voorspools K., William D'haeseleer D., 2005. Are deterministic methods suitable for short term reserve planning? Elsevier, Energy Conversion and Management, 46, 2042-2052.

Warwick-HRI, FEC Services Ltd, 2007. AC0401: Direct energy use in agriculture: opportunities for reducing fossil fuel inputs. DEFRA Report.

Wiggering H., Dalchowa C., Glemnitz M., Helming K., Müller K., Schultz A., Stachowa U., Zander P., 2006. Indicators for multifunctional land use-Linking socioeconomic requirements with landscape potentials. Elsevier, Ecological Indicators, 6, 238-249.

WRI, WBCSD, 2010. The Greenhouse Gas Protocol Initiative, http://www.ghgprotocol.org/ .

Zero Carbon Britain (ZCB), Centre for Alternative Technology, 2010. Zero Carbon Britain 2030: A New Energy Strategy; The $2^{\text {nd }}$ report of the ZCB project. Martin Kemp eds. 